\title{
Condition Monitoring and Predictive Modelling of Coating Delamination within Remote and Stationary Assets
}

\author{
Jawwad Latif, Zulfiqar A Khan, Mian H Nazir \\ Bournemouth University, Department of Design \& Engineering, NanoCorr, Energy and Modelling \\ (NCEM) \\ Keith Stokes \\ University of Southampton, National Centre for Advanced Tribology at Southampton (nCATS) Faculty \\ of Engineering and the Environment, Southampton SO17 1BJ \\ Joseph Plummer \\ Physical Sciences Division, Defence Science \& Technology Laboratory DSTL, Ministry of Defence, \\ Porton Down, Salisbury, SP4 0JQ
}

Keywords: Corrosion, Coating delamination, Condition monitoring, Diffusion, Predictive modelling

\begin{abstract}
The ambiguous nature of meteorological parameters in uncontrolled environmental conditions makes it difficult to determine the structural integrity of stationary and mobile assets. The weather conditions for large vehicles, at The Tank Museum at Bovington United Kingdom, which are operating under controlled and uncontrolled environmental conditions are investigated through weather history and corrosion monitoring techniques applied to large military vehicles by using linear polarisation resistance method. Corrosion reactions were found on several occasions during the operation of large vehicle within uncontrolled environment due to critical level of metrological parameters including salinity, relative humidity and rainfall. Comprehensive solutions have been proposed to detect damage initiation at the earliest possible stage to prompt maintenance professionals to take necessary actions to avoid damage. Early detection techniques will help to prolong the service life of large vehicles or metal structures which are operating or installed remotely. The analysis of diffusion of salt particles into coating during summer and winter season is also presented by estimating the salt concentration by taking linear relationship between wind speed and salt deposition rate based on ISO classification of airborne salinity. The proposed solutions can be applied to valuable assets operating in both noncoastal and coastal regions, near the sea, to predict and estimate the damage.
\end{abstract}

\section{Nomenclature}

$\begin{array}{cl}\mathrm{I}_{\text {Corr }} & \text { Corrosion current density } \\ \mathrm{B} & \text { Proportionality constant } \\ \mathrm{R}_{\mathrm{p}} & \text { Polarisation resistance } \\ w & \text { Atomic weight } \\ A & \text { Area of corroding electrode } \\ e & \text { Number of electrons exchanged } \\ F & \text { Faraday's constant } \\ C R(t) & \text { Corrosion current rate } \\ \partial S / \partial t & \text { Change in concentration with respect to time } \\ D_{A_{S}} & \text { Standard diffusion coefficient }\end{array}$




\begin{tabular}{|cl|}
\hline$T$ & Temperature \\
$R H$ & Relative Humidity \\
$t$ & Time of exposure \\
$F_{x}$ & Vertical flux for aerosol \\
$v_{d}$ & Deposition velocity \\
$d S_{s} / d t$ & Rate of change of salt concentration near sea \\
$S_{s}$ & Salt concentration near sea \\
$S_{0}$ & Initial salt concentration \\
$x$ & Distance from sea \\
\hline
\end{tabular}

\section{Background}

According to NACE International report, the global cost of corrosion is $3.4 \%$ of the global GDP (Gross Domestic Product) which is equal to the US \$2.5 trillion [1]. Corrosion related repairs and maintenance costs are around $23 \%$ of the budget within the military applications in the US. It will lead to significant cost savings in the range of 15 to $35 \%$ by preventative measures, avoiding malfunctions, downtime and enhancing reliability [2]. Several methods and techniques have been adopted for predicting corrosion damage by using the neural network, mathematical models and probabilistic approaches. Literature provides extensive experimental observations regarding the influence of meteorological factors on materials' corrosion behaviour subject to various geographical locations and operating conditions. The attempt has been made to propose universal equations by finding the correlation between exponent of power-law and meteorological parameters to predict corrosion damage in $[3,4]$. The information about annual corrosion data of rural and urban atmospheric quality from almost 28 countries was compiled to develop a mathematical equation for estimation of corrosion damage of several materials including mild steel, aluminium, copper and zinc [insert ref]. The mathematical relations derived from the data recorded were not promising to estimate the corrosion damage. The complexity and uncertainty in corrosion phenomena have encouraged researchers to include the effect of other potential meteorological factors which are responsible for corrosion damage into the mathematical models to derive generalised equations which could be suitable for any location. The annual corrosion rate of carbon steel was observed in 43 different sites and regression equations were proposed to estimate corrosion rate [5]. The corrosion study of carbon steel under indoor and outdoor Cuban atmospheres was conducted to propose corrosion model [6]. The results from experimental data have shown significant variations in corrosion under various atmospheric conditions and exposure time.

In previous mathematical models, the corrosion loss is not zero even in the absence of water. The model was proposed [7] which incorporates time-of-wetness, salinity, sulphur dioxide and temperature to predict corrosion loss and the appropriate form of time-of-wetness is added to show zero corrosion in the absence of water. The field exposure tests were conducted in an urban, rural-wet, rural-dry and marine environment of Sri Lanka for the development of corrosion model [8]. The results concluded that the prediction of corrosion loss from models show good performance when they are calibrated according to their location. After applying power law function on field exposure corrosion data, the concave functionality of power law function does not sound to be an appropriate 
solution for real-time corrosion prediction assessment as the environmental factors vary significantly over the location and from location to location [9]. The probabilistic techniques had also been applied to model the corrosion growth phenomena. In [10] the prediction of corrosion damage has been developed by using the current corrosion condition of material and growth of corrosion rate as input parameters for the probabilistic model.

Various types of metal-coatings including thermal spray coating, organic coating, corrosion-resistant coating and chemically resistant coating are applied to civil, automotive and engineering infrastructures to make a physical barrier between metal structures and atmosphere to provide protection from meteorological factors such as moisture, corrosive ions and oxygen [11]. The coating barrier also leads to failure in the form of porous medium, cracks and blisters. The corrosive ions can diffuse into the coating-substrate system through defected coating or porous medium and activates electrochemical reaction which results in the degradation of the metal structure and coat-substrate bond weakening [12]. Various techniques have been adopted to investigate the role of corrosive ions diffusing into the coating-substrate system in the past. Special electrochemical cell was developed to investigate the relation between cathodic or anodic current and coating delamination under the coating for zinc polymer system [13]. The diffusion of water and oxygen into the coating-substrate system was investigated in the presence electrochemically active sites [14-18]. It was found that the organic coating doesn't provide sufficient protection against dissolution of water and oxygen which decreases the adhesion between coating and substrate. According to the conclusion derived from research findings in $[15,17]$, the delamination of coating in the defected area is driven by the strength and diffusion of corrosive ions as the coating starts behaving like a jelly medium where electrochemical cells are active. The mathematical model [19] was developed to describe the delamination behaviour of coating by using the relation between porosity and $\mathrm{pH}$ which was an adequate approach to couple the experimental findings in the past [17] and analytical modelling. The concept proposed in [19] was adopted to further develop a mathematical model for coating delamination in the presence of homogeneous reactions, electrochemical reactions and precipitation of corrosive ions in [12]. Currently, researchers have been using multi-disciplinary approaches to model the coating delamination process by using solid mechanics, material science and fracture mechanics concepts. Coating life assessment models were developed by using weight functions, diffusion concepts and stress intensity factors based on the principles of mesomechanics and approach [20,21].

NanoCorr Energy and Modelling (NCEM) research group have been working to provide solutions to detect and mitigate the potential threats posed to large vehicles stationed at The Tank Museum, Bovington, United Kingdom [22-49] by electrochemical degradation combined with mechanical failures. Current research provides contribution towards detection, prevention and the assessment of material and coating degradation of high-value assets in operation or stationed indefinitely and could be at remote locations both under controlled and uncontrolled environmental conditions.

The past weather history at The Tank Museum Bovington, UK is reported in current work where linear polarisation technique was applied to measure the environmental impact on large vehicle operating under both controlled and uncontrolled environmental conditions. The solution is also proposed for large vehicles operating at remote locations to detect the critical environmental conditions at the earliest stage. The analysis of the diffusion of corrosive ions into the coatingsubstrate system is also presented by estimating salt concentration. According to literature, the deposition rate of salt depends on wind speed [50-53]. The classification of airborne salinity which defines salt deposition rate based on location is utilised to estimate the concentration of salt by assuming linear the relation between wind speed and deposition rate based on experimental observations performed in the past $[50,54,55]$. The analysis is conduction for summer and winter 
seasons. Furthermore, the mathematical relation is also presented for the diffusion of salt particles for assets near the sea.

\section{Weather conditions}

The weather conditions of last few years at The Tank Museum is analysed by using data taken from world weather online [56]. The minimum wind speed for entrainment of salt particles is $3 \mathrm{~m} / \mathrm{s}$. The wind speed during last year at Dorset, The South West Coast of England United Kingdom is provided in fig. 1. It can be seen that the average wind speed remains greater than the threshold level for aerosol entrainment of salt particles. The presence and deposition of salt particles over large vehicles can be expected throughout the year in an uncontrolled environment. The relative humidity of last the three years at Dorset is shown in Fig. 2. According to the literature, the critical humidity level above which corrosion process is more likely to take place is around $80 \%$. The history of relative humidity shows that most of the time during a calendar year the relative humidity level remains greater than the critical level. One of the most important factors which are responsible for corrosion reaction is the rain. The data of number of rainy days during the last three years is presented in fig. 3. The water and salt are the main ingredients for corrosion reaction. The speed of wind greater than the threshold level for entrainment and large number of rainy days throughout the calendar year makes large vehicles more vulnerable to corrosion damage.

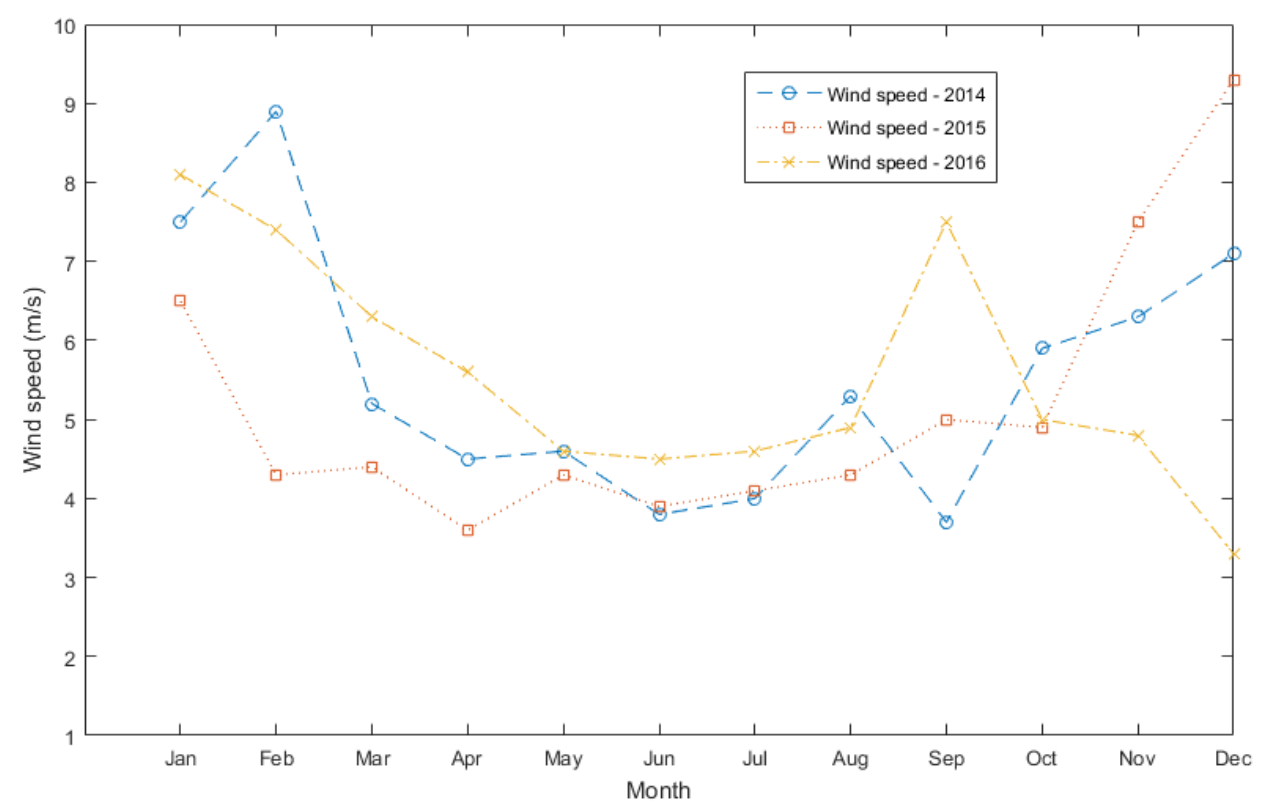

Figure 1 Wind speed in Dorset, UK during last three year [56]

The source of salinity is the English Channel within the vicinity of the Bovington which is 5.6 miles away from the Atlantic Ocean. Several tanks are also stationed at random locations in Dorset near the Atlantic Ocean under significantly harsh environments. One of the large vehicles, Valentine, which is operating in controlled and uncontrolled environmental conditions from the past several years in The Tank Museum, United Kingdom was considered for investigation of corrosion reaction. Significant corrosion damage has been found on several parts of Valentine tanks as shown in fig. 4. The Tank Museum Bovington United Kingdom owns a large number of around 300+ large military vehicles (military tanks). These military tanks were exposed to harsh working and operating conditions in the battlefields in their past service life and therefore showing various modes of degradation in their structures. Corrosion can be classified as one of the major contributors to the structural ageing of the 
military tanks. NCEM has investigated several vehicles to identify corrosion problem and other associated damages and risks. The investigation has revealed the several types of corrosion were prevalent and some vehicles showing severe corrosion problems in their structures. Several problems were identified [57] in the large vehicles and few of them are shown in Fig. 4.

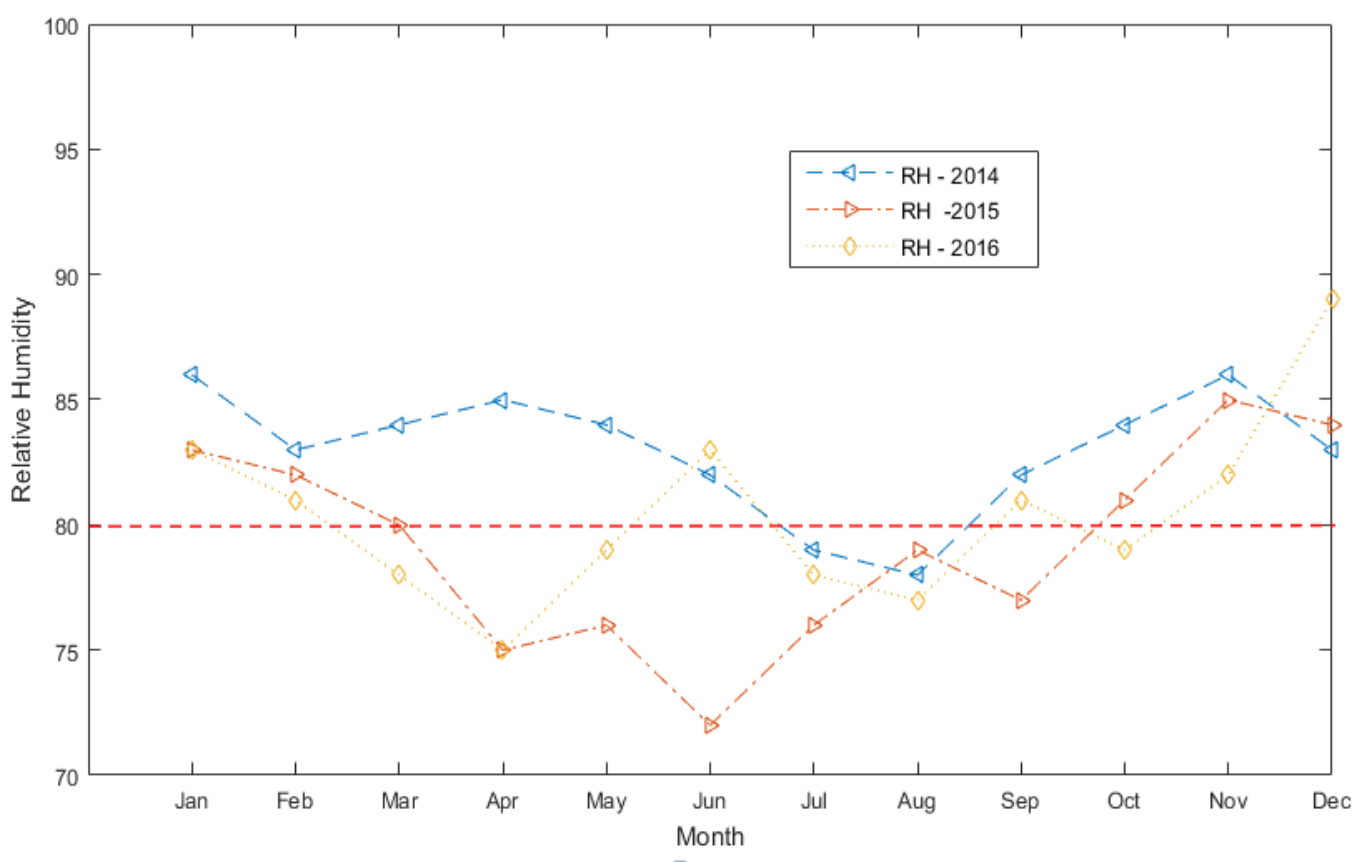

Figure 2 Relative Humidity in Dorset, UK during last three years [56]

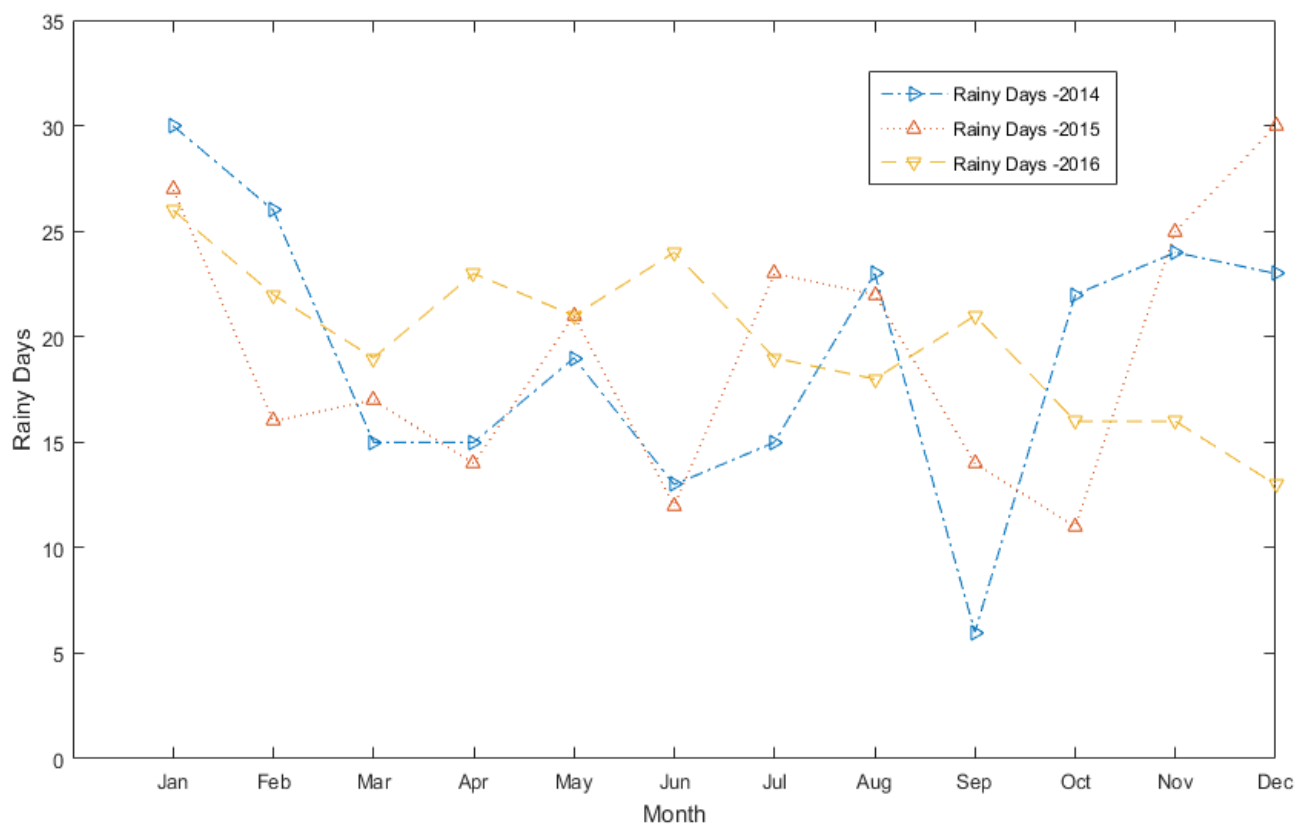

Figure 3 Rainy days in Dorset, UK during last three years [56]

The large vehicles were operated under controlled and uncontrolled environmental conditions. The surface coating failure on Challenger-1 can be observed in fig. 4(a). The breakdown of the coating is revealing the structure of tank and failure is propagating with time due to meteorological factors and properties of the coating-substrate system. The fig. 4(b) is showing how corrosion problem in a 
component of Tiger Tank is leading to structural failure. Centaur was badly affected by various corrosion modes. Inter-granular (IGC) corrosion is a localised corrosion attack on or at the grain boundaries propagating into the material. Inter-granular corrosion damage was identified in Centaur armoured skirt as shown in fig. 4(c). Uniform corrosion has been identified on several tanks; a sample from the tank is shown in fig. 4(d) [29, 39, 57-59]. Conclusively, the large number of rainy days, wind speed and relative humidity makes the conditions critical for large vehicles and structures to be prone to corrosion.

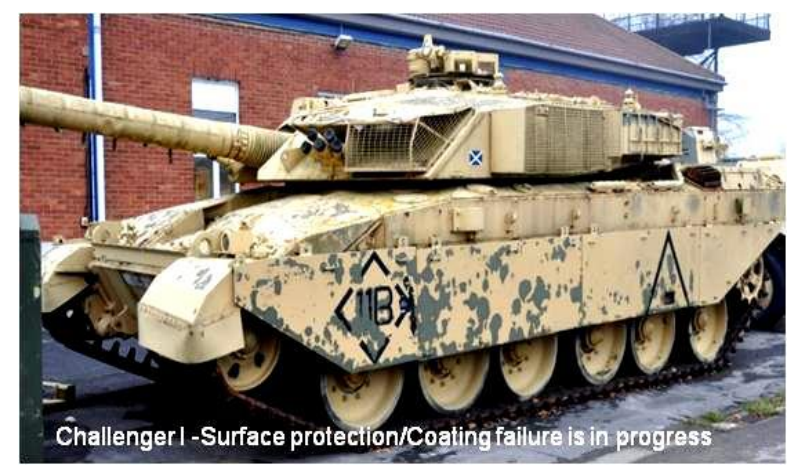

(a) Surface protection breakdown

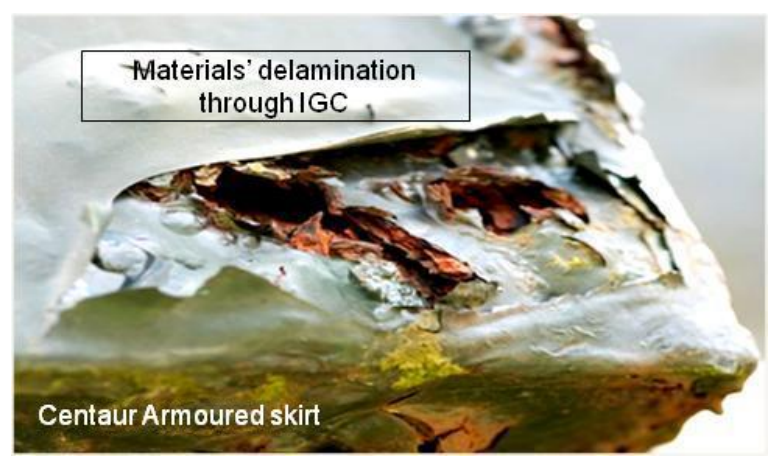

(c) Inter-granular corrosion in the armoured skirt

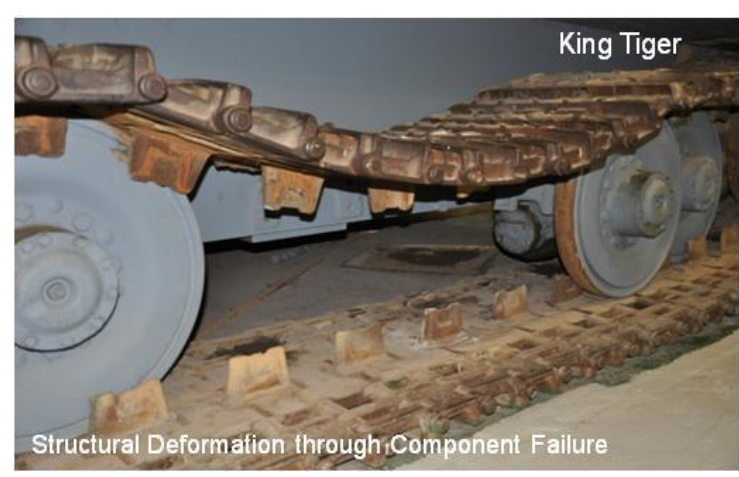

(b) Structural deformation due to component failure

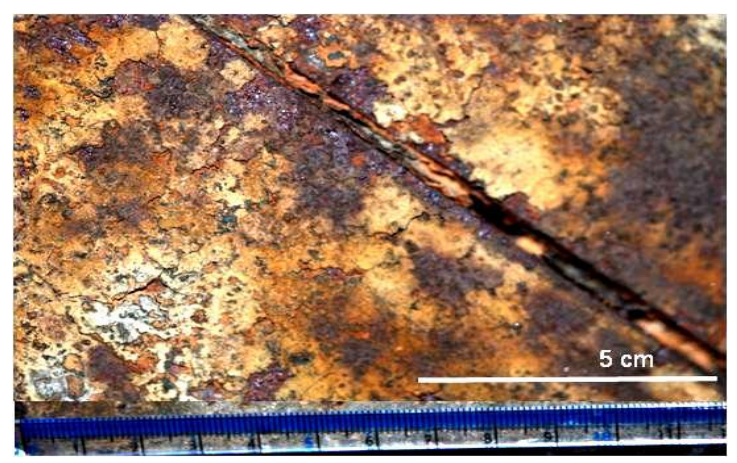

(d) Uniform corrosion

Figure 4 Coating failures and structural damage of Valentine tank operating under uncontrolled and controlled environmental conditions at The Tank Museum. UK [59]

\section{Experimental Analysis}

Corrosion is an electrochemical reaction in which metals in manufactured states turns back to its natural states which results in deterioration and loses in the functional stability of metals. The oxidation reaction occurs on the metal surface due to its surrounding environment including water and oxygen to form rust. A corrosion reaction is illustrated in fig. 5 in which the anodic site of metal is losing electrons to produce $\mathrm{Fe}^{2+}$ ions.

$$
\mathrm{Fe}_{(s)} \rightarrow \mathrm{Fe}^{2+}{ }_{(\mathrm{aq})}+2 e^{-}
$$

The cathode site reacts with electrons, water and oxygen to form hydroxide $\left(\mathrm{OH}^{-}\right)$ions.

$$
\mathrm{O}_{2}+2 \mathrm{H}_{2} \mathrm{O}+4 e^{-} \rightarrow 4 \mathrm{OH}^{-}
$$


The $\mathrm{Fe}^{2+}$ and $\mathrm{OH}^{-}$reacts with each other to form $\mathrm{Fe}(\mathrm{OH})_{2}$ which is called rust.

$$
\begin{gathered}
\mathrm{Fe}_{(a q)}^{2+}+2 \mathrm{OH}_{(a q)}^{-} \rightarrow \mathrm{Fe}(\mathrm{OH})_{2(s)} \\
4 \mathrm{Fe}(\mathrm{OH})_{2(s)}+\mathrm{O}_{2(\mathrm{~g})}+2 \mathrm{H}_{2} \mathrm{O} \rightarrow \mathrm{Fe}(\mathrm{OH})_{3(s)}
\end{gathered}
$$

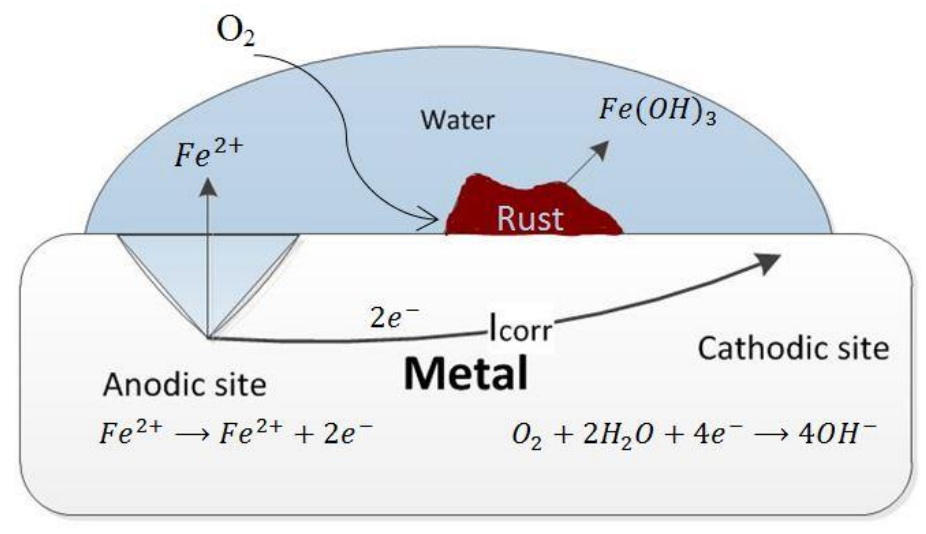

\section{Figure 5 Corrosion reaction}

The existence of salt particles in water acting as electrolyte boost the conductivity of water which results in an effective increase of the concentration of ions and so stimulating the oxidation process (corrosion) of metal. In electrochemical techniques, Linear Polarisation Resistance method provides an effective technique for condition monitoring of metal infrastructures by detecting corrosion reaction due to environmental effects. The $\mu$ LPR sensor has been developed on linear polarisation theory to directly detect the corrosion in real time caused by water, oxygen and salt. The modern research on corrosion is based on mixed potential theory hypothesised by Wagner and Traud that the overall corrosion reaction is the summation of autonomously occurring oxidation-reduction reactions [60]. The corrosion is measured by computing the flow of current $\left(I_{\text {corr }}\right)$ during oxidation-reduction reaction between anodic and cathodic sites. The sensor has three electrodes including working electrode, counter electrode and reference electrode.

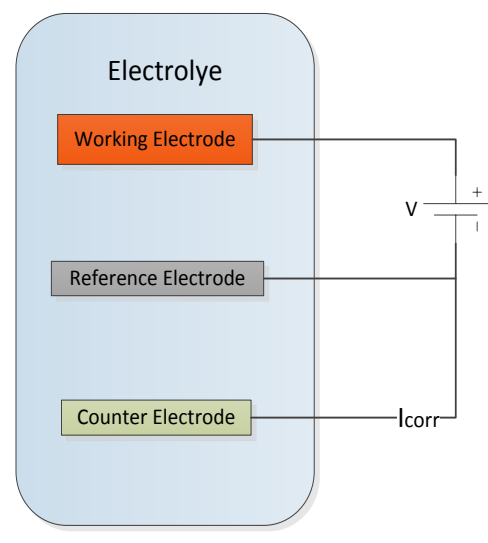

Figure 6 Three electrode system

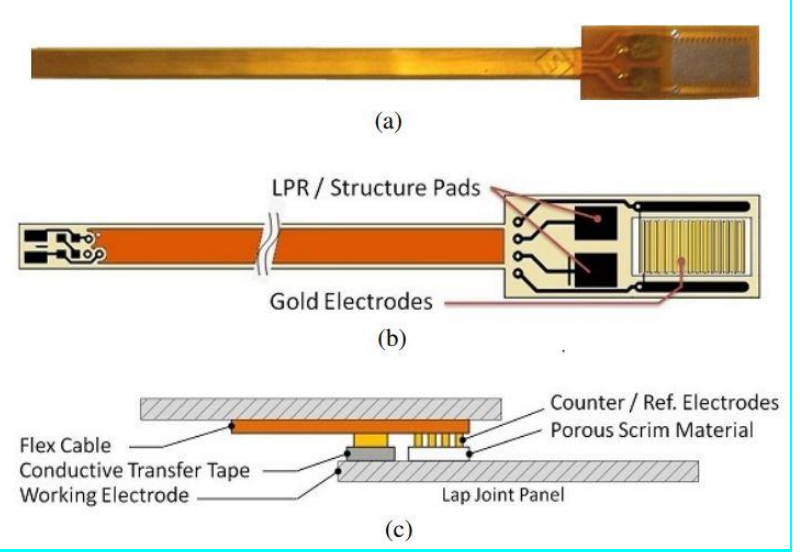

Figure 7 Structure of $\mu$ LPR sensor [61] 
The oxidation reaction takes place at working electrode while counter electrode completes the circuit. The reference electrode acts as a half cell which allows the potential of the other half-cell to be measured. The three electrode system and structure of $\mu$ LPR sensor is shown in fig. 6 and fig.7.

The performance of $\mu$ LPR sensors was tested for degradation detection in bridge suspension cable [62]. It has been found one of the most feasible solutions for monitoring the environmental impact on high-value infra-structures such as aircrafts, bridges and buildings. The uLPR sensor very sensitive to corrosion is fabricated through a photolithographic process. It contains shim which is prepared using Electro-Chemical Etching and photolithographic techniques. The shim is further machined on the Kapton to enhance robustness and ductility. In the current research, $\mu$ LPR sensors have been utilised to detect the corrosion reactions due to the environmental impact on large vehicles at The Tank Museum, UK. In order to analyse the condition of large vehicles operating in uncontrolled environmental condition, $\mu$ LPR sensors were installed at turret top of Valentine tank as shown in fig. 8 and condition were monitored for the duration of over two years. Sensors were further connected with data acquisition units to perform signal conditioning and data acquisition. The Stern-Geary equation can be used to calculate the corrosion current density after acquiring polarisation resistance values from the $\mu \mathrm{LPR}$ sensors $[60,61]$.

$$
\begin{gathered}
I_{\text {Corr }}=\frac{B}{R_{p}} \\
C R(t)=I_{\operatorname{Corr}}\left[\frac{w}{A * e * F}\right]=\frac{B}{R_{p}}\left[\frac{w}{A * e * F}\right]
\end{gathered}
$$

In eq. $1, I_{\text {Corr }}$ represents the corrosion current density which can be computed by taking the ratio of polarisation resistance $\left(R_{p}\right)$ and Stern-Geary constant $(B)$. The value of Stern-Geary constant $(\mathrm{B})$ is $30 \mathrm{mV}$ for carbon steel $1010[61,63]$. In eq.2, $C R(t)$ represents corrosion rate, $F$ represents Faraday's constant, e represents the number of electrons exchanged, $w$ represents atomic weight and $\mathrm{A}$ is the area of corroding electrode.

At The Tank Museum, Bovington, Large vehicles are involved in several activities as some of them
are stationed inside the museum for display under the shed, where the controlled environmental
conditions are provided and some of the vehicles are moved outside in uncontrolled environmental
conditions. The $\mu$ LPR sensors were installed at turret top of Valentine tank which was operated inside
the shed in controlled environmental conditions and also operated remotely outside shed under
uncontrolled and harsh environmental conditions of Dorset as described in previous sections. The
$\mu$ LPR sensors were constantly monitoring the corrosion process during inside operation and remote
activity. 


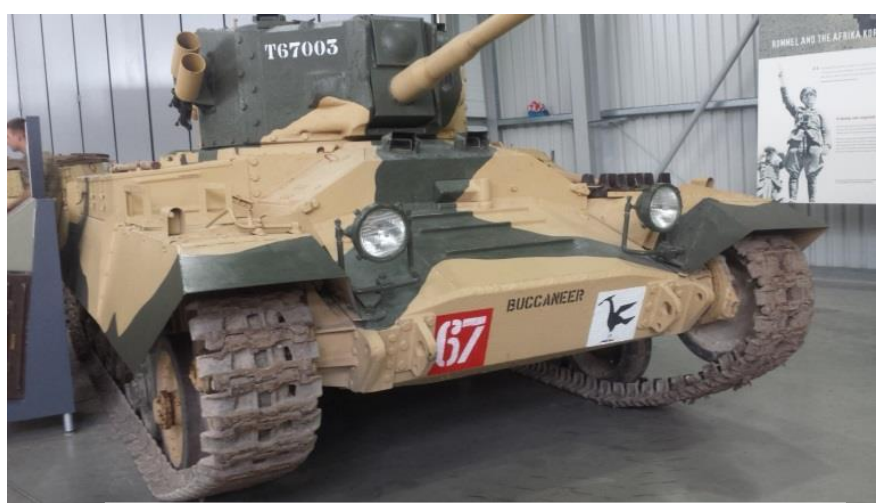

(a) Valentine Tank stationed at The Tank

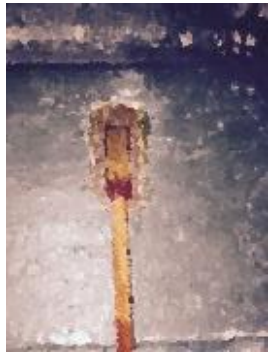

(b) $\mu \mathrm{LPR}-1$ sensor

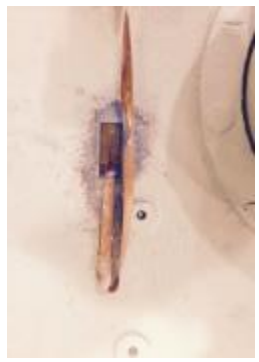

(c) $\mu \mathrm{LPR}-2$ sensor

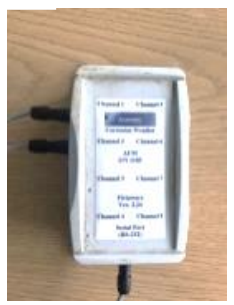

(d) DAQ connected to sensors

Figure 8 Valentine tank and sensing instruments at The Tank Museum, UK

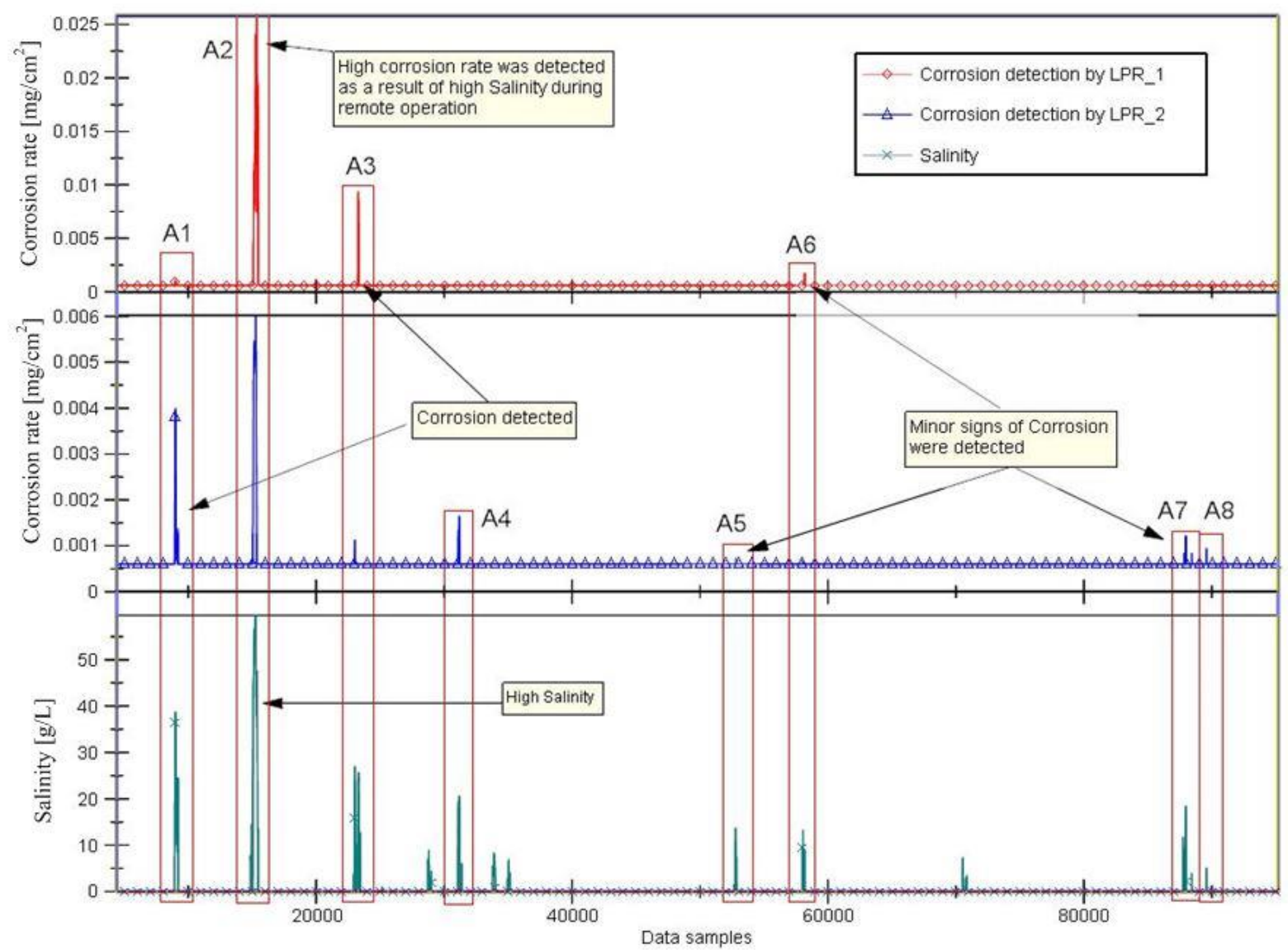

Figure 9 Corrosion detection from $\mu$ LPR sensors at Turret top of Valentine tank during stationary and remote activities 
Approximately, 90k data samples have been recorded from $\mu$ LPR sensors. The measurements taken from sensors are plotted in fig. 9 where remote activities which were repeated several times are labelled as A1, A2...A8. The Valentine tank was operated remotely 8 times during the corrosion monitoring period. It can be seen in the results plotted in fig. 9 that no sign of corrosion has been detected in controlled environmental conditions while corrosion has been detected several times during remote activity of Valentine tank. The salinity in outside atmosphere can be considered as a major contributor to corrosion reaction as the increase in salinity resulting in high corrosion rate as. The highest corrosion rate was detected by both $\mu$ LPR sensors during remote activity A2 as the corresponding value of salinity also highest. The accumulative corrosion detected by both $\mu \mathrm{LPR}$ sensors during remote activities $\mathrm{A} 1$ and A3 is less than the corrosion detected during $\mathrm{A} 2$ as the salinity level is also low. The measurements have been recorded during all the remote activities while the results of activities A1, A2and A3 are shown in fig. 10, fig. 11 and fig. 12. The $\mu$ LPR sensors have shown similar behaviour in all activates as the salinity level is increasing, the corrosion rate is also increasing and decrease in salinity level making corrosion rate decrease accordingly. The corrosion rate detected during activities A5, A6, A7 and A8 is very low as the corresponding salinity level is also very low.

The conclusion can be drawn that in uncontrolled environmental conditions the salinity in the atmosphere is a major element to cause corrosion damage as other factors including rain, temperature and humidity are already above the critical level for most of the time during a calendar year.

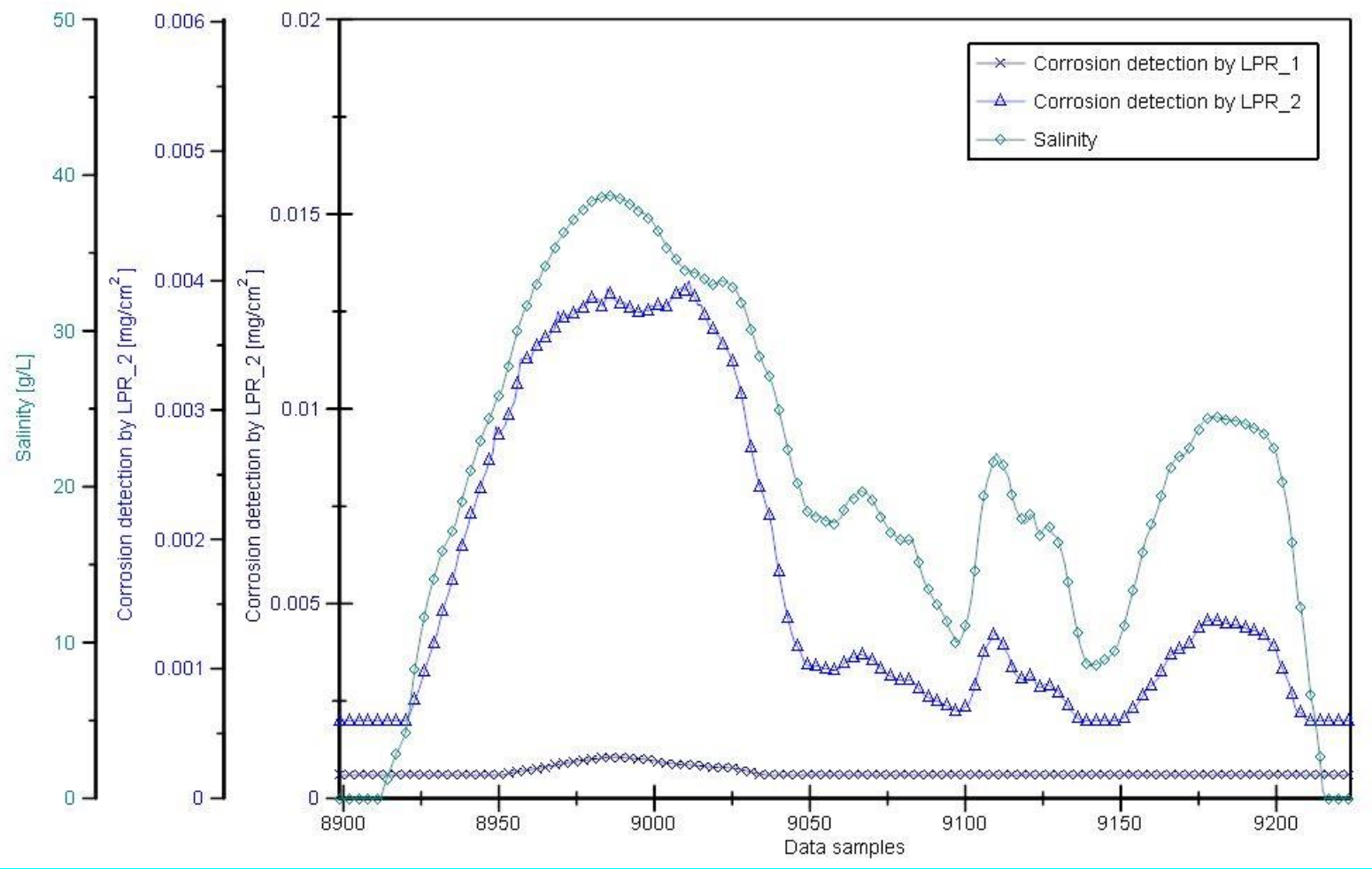

Figure 10 Corrosion rate and Salinity measurements during remote activity A1 


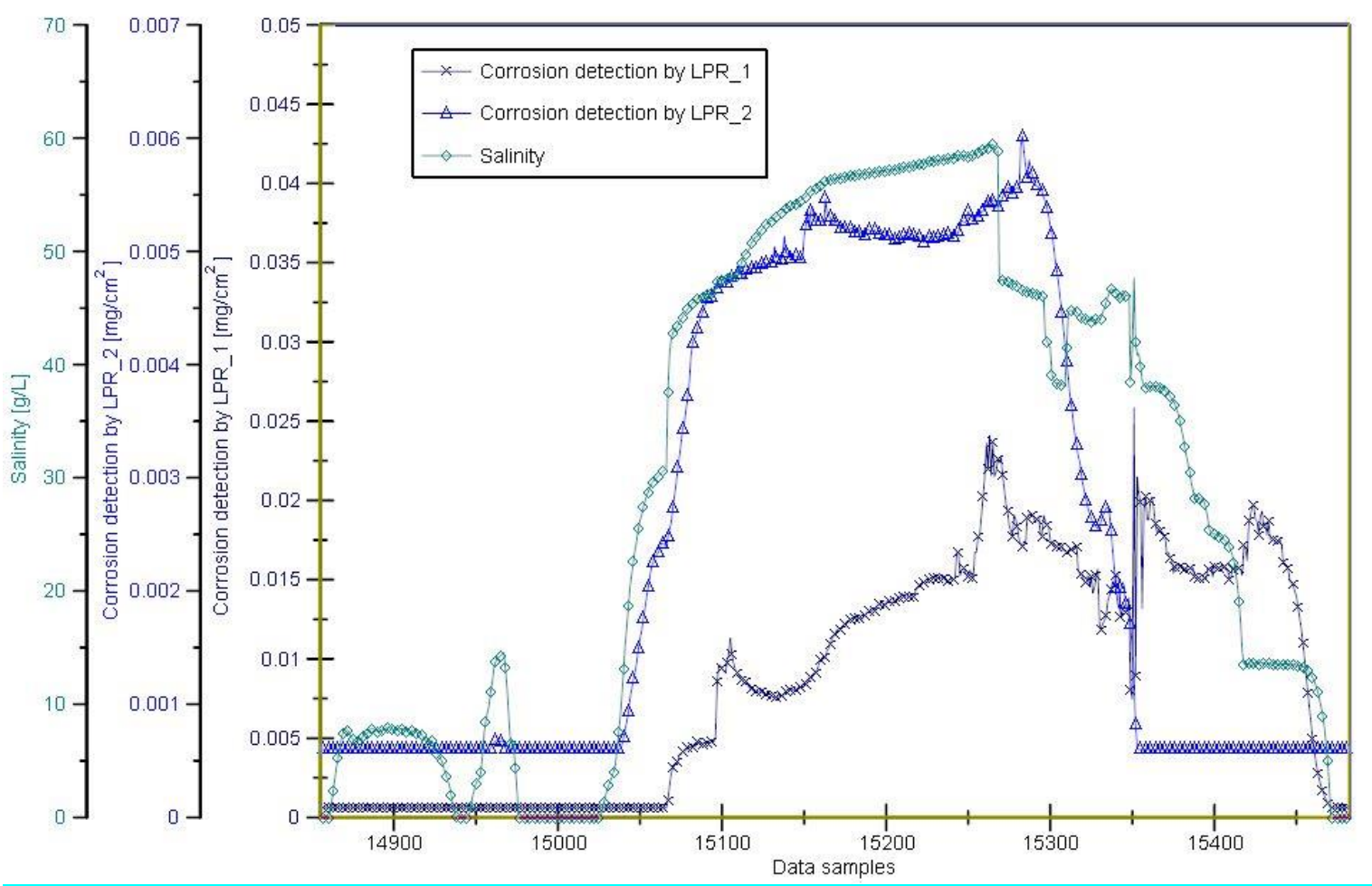

Figure 11 Corrosion rate and Salinity measurements during remote activity A2

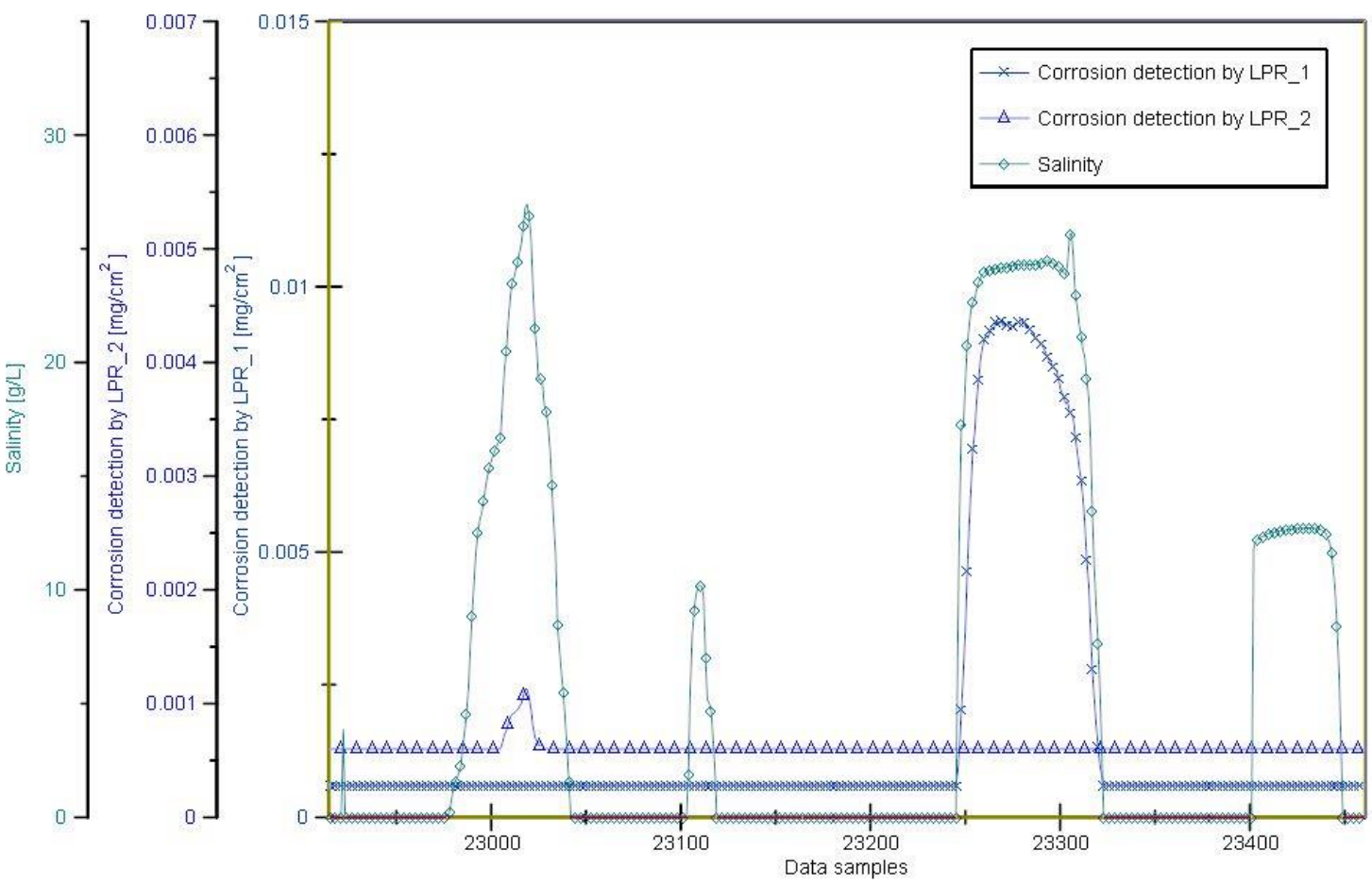

Figure 12 Corrosion rate and Salinity measurements during remote activity A3 


\section{Corrosion monitoring for remote assets}

Due to the uncertainty in metrological factors for stationary and remote vehicles operating in an uncontrolled environment, it is very important to find a solution to detect the threat to vehicles at the earliest possible stage to avoid any damage and prolong the service life. The performance of $\mu \mathrm{LPR}$ sensors to measure the environmental impact on the large military vehicle has been investigated at The Tank Museum as mentioned in the previous section. The complex structure of vehicles makes it difficult to access and assess every part of large vehicles on a continuous basis. The corrosion monitoring system which was implemented for corrosion detection had data acquisition unit with internal memory to store data values and data was retrieved by connecting an external device such as a laptop for further analytical investigations.

A comprehensive solution is required for high-value assets which are operating at remote locations such as large military vehicles to receive real-time information about critical conditions on time. The use of $\mu \mathrm{LPR}$ sensors and wireless system technology can provide an efficient way for detection of critical environmental conditions. The system consists of a suite of $\mu$ LPR sensors, data acquisition unit and remote terminal unit. The sensor is responsible for measuring the impact of environmental changes as described in the previous section. The data acquisition unit performs signal condition and forwards it to the remote terminal unit. The wireless transmission is carried out at a remote terminal unit which has General Packet Radio Service (GPRS) technology. It utilises cellular network to send and receive messages from remote locations. The advantage of using GPRS technology is that the information regarding corrosion damage can be transmitted or received even from mobile vehicle operating at a remote location. The information regarding the impact of environmental conditions on vehicles or high-value assets stationed or operating at mobile locations will help the maintenance professionals to take necessary steps in order to avoid costly damages due to corrosion. Maintenance or precautionary actions by the professionals could be the movement of vehicle or asset to the appropriate location and it could be the dusting or cleaning mechanism to remove any corrosive products over the body surface to stop corrosion or delamination process. The remote monitoring system has shown in fig. 13 which consists of sensors, data acquisition unit, remote terminal unit and application software.

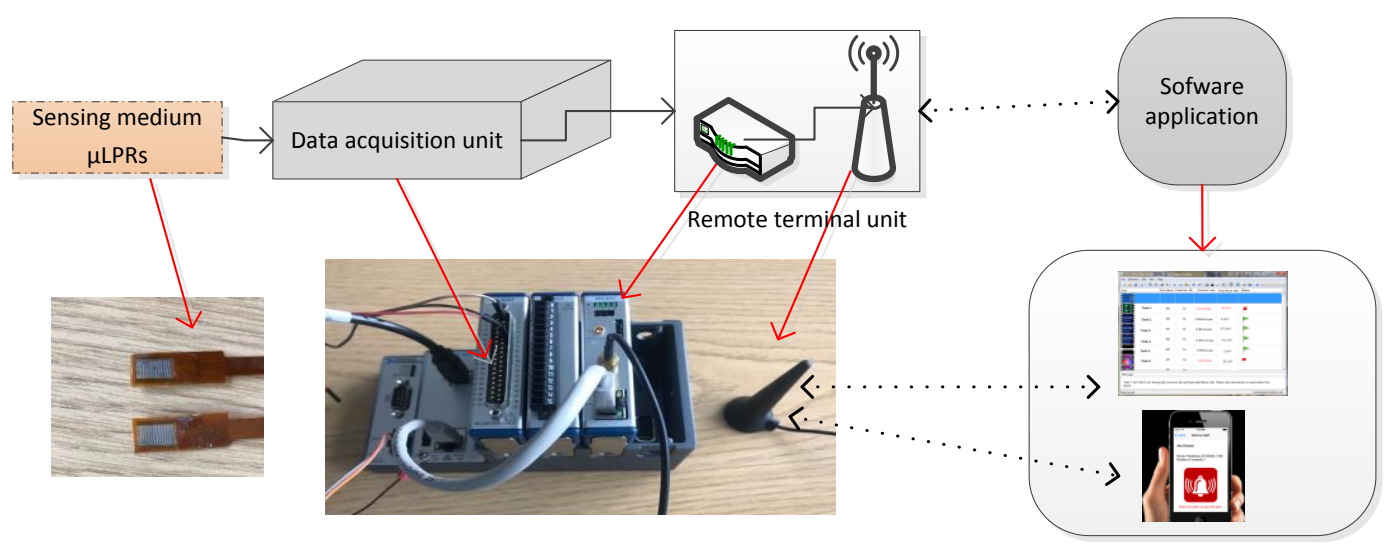

Figure 13 Corrosion monitoring system model for remote assets 


\section{Modelling of coating delamination}

The delaminated porous region in coating allows the salt particles to diffuse into the interface of the coating-substrate system and propagate towards the intact region. The rate of corrosion current density is directly related to salt concentration which means high diffusion rate will result in high delamination due to corrosion current density which is proportional to metal loss. The salinity in the atmosphere, relative humidity, temperature, time of exposure, rain and wind speed around the highvalue assets such as large vehicles are responsible for coating delamination process. The variation in weather conditions makes it difficult to estimate the delamination phenomenon in a more realistic way. The deposition of an amount of salt particles over the body of a large vehicle is the major factor to decide the level of damage. According to research findings in the past, wind speed plays a major role in the deposition rate of salt particles and both are proportional to each other unless other factors like crosswind or shape of body affects the accumulated salt concentration. ISO classification of airborne salinity for atmospheric salinity has been utilised to estimate the salt concentration over body depending on the location of an asset such as coastal region, non-costal region or near the sea.

\subsection{The diffusion of hygroscopic ions into metal coating}

The accumulation of corrosive ions on large military vehicles at The Tank Museum depends on uncertain vehicle movement and variation in the environmental conditions. The diffusion process depends on various factors including the concentration of ions, temperature, relative humidity and time of exposure. The change in the concentration of ions can be interpreted as a summation of diffusion, migration and convection process [64].

$$
\begin{gathered}
\frac{\partial S}{\partial t}=\text { diffusion }+ \text { migration }+ \text { convection } \\
\frac{\partial S}{\partial t}=\frac{1}{n} \sum_{S_{e_{n=1}}}^{n}\left[D_{A_{s}}(T, R H, t) \nabla S_{e}+z D_{A_{s}} S_{f} \nabla \emptyset+j_{m} S_{f}+R_{S}+S_{S}\right]
\end{gathered}
$$

The migration and convection processes are neglected in the current research. $D_{A_{S}}$ is the diffusion coefficient which is smaller by two order magnitude in a porous medium as compared to in aqueous medium [19].

$$
D_{A_{S}}=\left[\frac{1}{D_{S, S T A} f(T) f(R H) f(t)}\right]^{2}
$$

\subsubsection{Salinity model}

The concept of aerosol physics describes the deposition of hygroscopic particles from the atmosphere on the solid surfaces. The aerosols are generated by various physical processes over the sea surface but the bursting of air bubbles is one of the common causes due to wind stress during the formation of Whitecap [65]. The wind speed is a key factor to determine the deposition rate of hygroscopic particles on the solid surface. The threshold level of wind speed for initiation of entrainment of marine aerosol found to be $3 m s^{-1}$ [51]. 
The deposition of salt particles over solid surface depends on many factors including wind speed, wind direction distance from the sea, surface roughness, particle density, shape of body and local landscape. The ISO classification of airborne salinity has classified the deposition rate into four categories and specified the range for a deposition rate of salt particles for the corresponding environmental category. It has four categories such as non-coastal environment denoted as $\mathrm{S}_{0}$. It has a maximum deposition rate of $3 \mathrm{mg} / \mathrm{m}^{2}$.day. The coastal environment has categories having a maximum deposition rate of $60 \mathrm{mg} / \mathrm{m}^{2}$. day denoted as $S_{1}$ and $300 \mathrm{mg} / \mathrm{m}^{2}$. day denoted as $S_{2}$. The location near the sea $\left(\mathrm{S}_{4}\right)$ can have a maximum deposition rate of $1500 \mathrm{mg} / \mathrm{m}^{2}$. day. Experimental observations conducted in the past has shown an increase in salt deposition rate as wind speed increases from 3.4 to $10 \mathrm{~m} / \mathrm{s}$ and other factors including crosswind affecting deposition rate is not included in the proposed algorithm.

Corrosion and coating delamination will vary from location to location as the deposition rate varies depending on wind speed. The uncontrolled environmental conditions can also be classified into four categories as $\mathrm{UC}_{0}$ for deposition rate $\mathrm{S}_{0}$ non-coastal region, $\mathrm{UC}_{2}$ for the deposition rate $\mathrm{S}_{2}$. $\mathrm{UC}_{3}$ for deposition rate $\mathrm{S}_{3}$ and $\mathrm{UC}_{4}$ for $\mathrm{S}_{4}$ deposition rate near the sea. In the current work, the ISO classification for salinity deposition rate has been utilised to estimate the accumulation of deposited particles over the solid body surface as a function of wind speed for coastal and non-coastal environmental conditions. For example, in the non-coastal environment, the maximum deposition rate is $3 \mathrm{mg} / \mathrm{m}^{2}$. day can be assumed for average wind speed. On the basis of experimental observations $[50,55]$ considering wind speed as a linear function of deposition rate and ignoring crosswind effects. Following algorithm is used to distribute the salt deposition rate over wind speed for simulation of various typical environments.

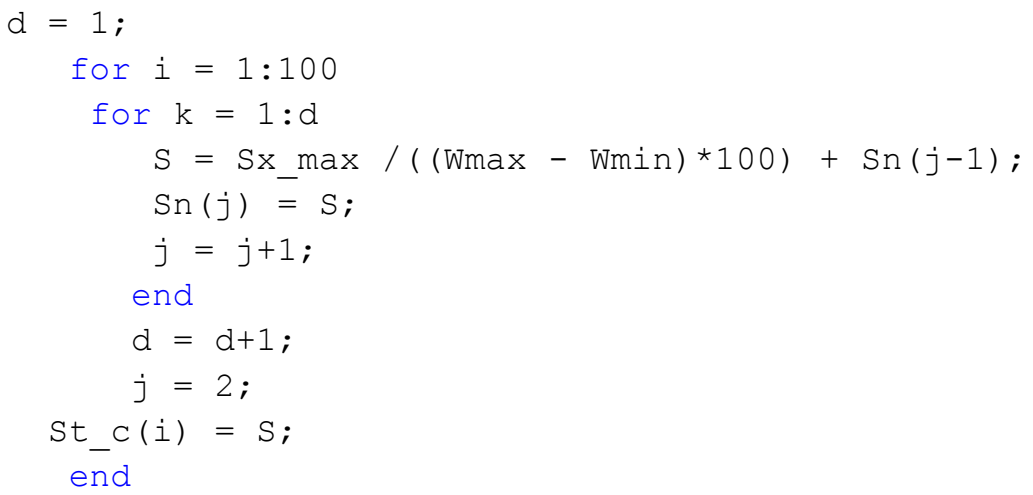

Sx_max is the maximum deposition rate as specified in the ISO standard. It can be for Non-coastal and coastal uncontrolled environmental conditions. Wmax is the maximum wind speed and Wmin is minimum wind speed depending on location.

The high amount of salt is present in the atmosphere near the sea. The equation is derived for transport rate of salt particles for structures near the sea as a function of distance and wind speed. The rate of change of concentration can be given as:

$$
\frac{d S_{s}}{d t}=-\frac{k S}{h}
$$

According to experimental observations in the past [66-69], the exponential decay of salinity was found as the distance from the sea increases, which was mathematically described as following: 


$$
S_{S}=S_{0} \exp (-k x / V h)
$$

Where $k$ co-efficient is proportional to deposition velocity [70], $\mathrm{V}$ is wind speed and $h$ is the height of air layer. The combination of diffusion mechanism and estimation of corrosive particles depending on wind speed and distance from the sea gives a comprehensive coating delamination model for more accurate and efficient prognostics of coating and corrosion near the sea. The fusion of eq. 3(b) and eq. 6 results in the following relation:

$$
\frac{\partial S}{\partial t}=\left[D_{A_{S}}(T, R H, t) S_{0} \exp (-\alpha x)\right]
$$

The proposed solutions can be used to estimate salt particles depending on the location as classified in ISO standard for airborne salinity. The transport rate of salt particles with a varying deposition rate as linear relation to the wind speed is simulated for summer and winter scenarios and also for near sea environment.

\subsubsection{Temperature model}

The atmospheric temperature plays a significant part in electrochemical corrosion reaction. The rate of chemical reaction depending on temperature can be computed from Arrhenius equation [71].

$$
T^{\prime}=A e^{\left[\left(\frac{G_{a}}{R}\right)\left(\frac{1}{T_{S T A}}-\frac{1}{T}\right)\right]}
$$

Where $A$ represents pre-exponential term, $G_{a}$ represents activation energy, $R$ represents universal gas constant, $T$ is the absolute temperature in Kelvin's and $T_{S T A}$ represents standard temperature. The

\begin{tabular}{|c|c|c|}
\hline \multicolumn{3}{|c|}{$\begin{array}{l}\text { ISO Classification of Pollution by Airborne Salinity } \\
\text { (Sodium Chloride deposition rate in Annual Average) }\end{array}$} \\
\hline Category & $\begin{array}{l}\text { Deposition rate of } \mathrm{NaCl} \text {, } \\
\text { mg/m2.day }\end{array}$ & Typical Environment \\
\hline $\mathrm{S}_{0}$ & $\leq 3$ & Non-Coastal \\
\hline $\mathrm{S}_{1}$ & 3 --- 60 & Coastal Environment \\
\hline $\mathbf{S}_{2}$ & 60 --- 300 & Coastal Environment \\
\hline $\mathrm{S}_{3}$ & $300---500$ & Within $200 \mathrm{~m}$. of Sea \\
\hline
\end{tabular}
standard diffusion coefficients $D_{S T A}$ for standard temperature $T_{S T A}$ are calculated in $[72,73]$.

Table 1 ISO classification of deposition rate of sodium chloride depending on different environmental conditions 


\subsubsection{Relative Humidity model}

The presence of moisture is an essential part for most of the corrosion reactions. If $R H$ is actual pore relative humidity and $R H_{S}$ represents relative humidity at which diffusion coefficient falls between maximum and minimum values then relation for relative humidity variation function can be given as:

$$
R H^{\prime}=\frac{1}{1+\left(\frac{1-R H}{1-R H_{S}}\right)^{m}}
$$

\subsubsection{Exposure time}

The deteriorating function depending on the time of exposure is given as [74]:

$$
t^{\prime}=\left(\frac{t_{S T A}}{t}\right)^{n}
$$

Where $t_{S T A}$ is time of exposure time at which standard diffusion coefficient is measured, $t$ represents actual exposure time and $\mathrm{n}$ is age reduction factor.

\section{Algorithm implementation}

The accumulation of salt particles over the structure of an asset which is changing its location and operating in dynamic and uncontrolled environmental conditions will vary significantly as compared to the asset operating stagnant in uncontrolled environmental conditions. The variation in concentration salt accumulation will vary the amount of transportation of salt particles into the coating-substrate system. The algorithm for estimating transport rate of salt particles is shown in fig. 9 which can be used for the assets operating in stationary conditions and also for those assets, which are installed remotely and moved to several locations in variable atmospheric conditions.

The algorithm takes temperature, relative humidity, time of exposure and wind speed as input parameters. The implementation of the algorithm using time iterative approach has been reported comprehensively in [74]. It also estimates the salinity transport rate by using deposition rate as mentioned in the ISO standard for airborne salinity. The reason behind using wind speed as an input is to estimate salt concentration by using wind speed readings of a particular location and utilises the value to make a more realistic prediction of transportation of salt particles into the coating-substrate system. The algorithm also has two decisional statements which depend on the change in the wind speed and change of location. If the location of asset changes (e.g. from non-coastal to coastal environment) the salt deposition rate values can be switched to the corresponding environment as defined in the ISO standard.

\section{Results and Discussions}

Multiple scenarios are considered to simulate the transportation of salt particles into the coating through porous medium. Various factors are responsible for the accumulation of salt particles over solid surfaces including surface roughness, location, wind speed, nature of pollutant, particle density and particle diameter. According to the literature [50-53], the wind speed also plays a major role in the accumulation of salt particles. The experimental observations performed at The Tank Museum by using $\mu \mathrm{LPR}$ sensors have detected different levels of corrosion rates at several times depending on 
salinity contents. The ambiguous nature of corrosion rates depending on diffusion coefficient and wind speed is simulated by considering multiple scenarios for deposition rate of salt particles depending on the increase and decrease in wind speed for summer and also for winter seasons. The ranges specified in the ISO standard for the deposition of salinity in different environmental conditions is utilised to distribute the deposition rate over different levels of wind speeds from $3 \mathrm{~m} / \mathrm{s}$ to $10 \mathrm{~m} / \mathrm{s}$. According to environmental categories specified in ISO standard, the uncontrolled environmental condition can also be classified into non-coastal, coastal and near sea uncontrolled environmental conditions.

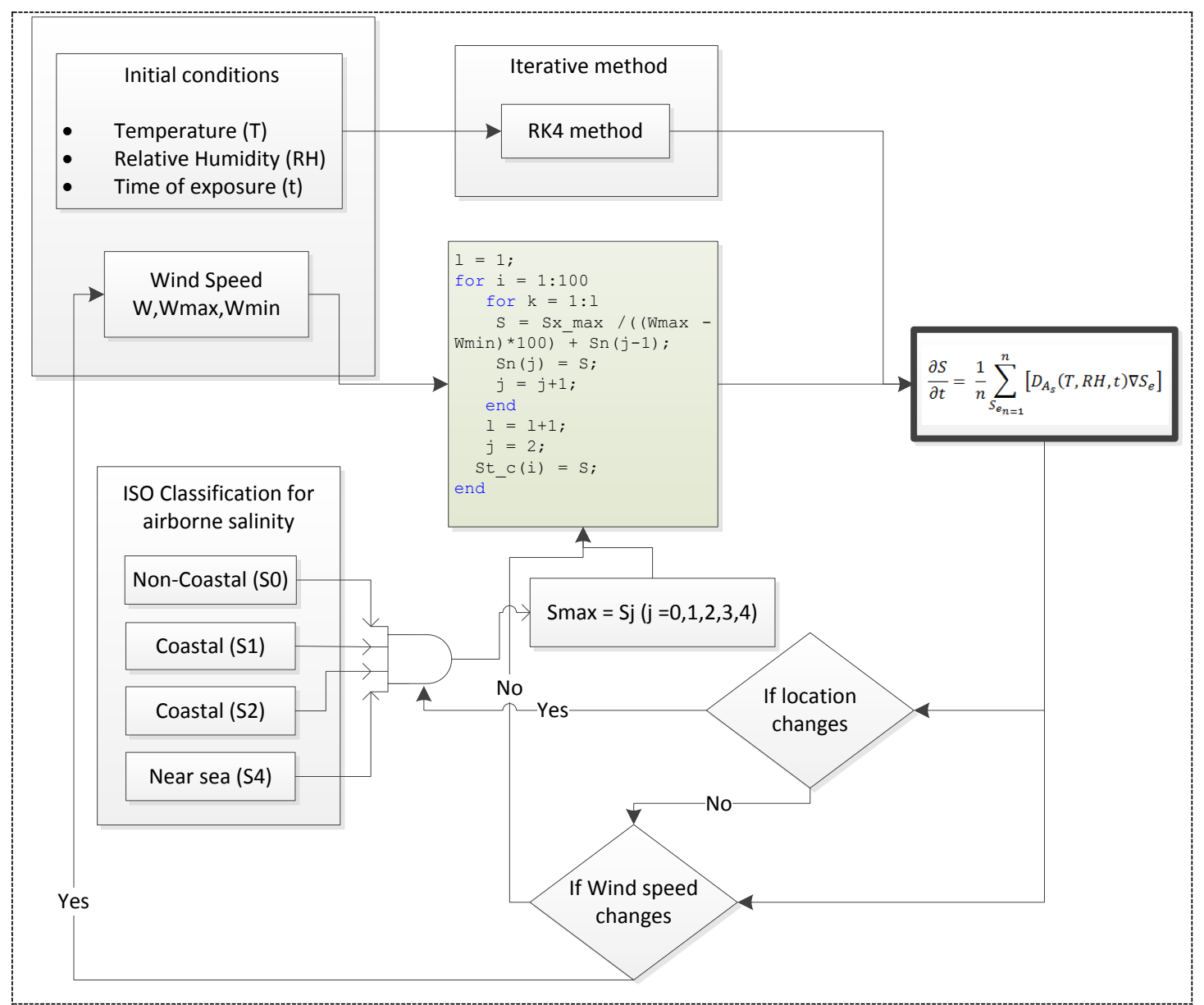

Figure 14 Algorithm for estimating salinity transport rate depending on various environmental conditions

The transport rate of salt particles in winter and summer seasons are considered with varying wind speed to understand ambiguous nature of delamination process. In the simulation, for the summer season, the temperature is kept on increasing, the increase in temperature also increases diffusion coefficient. The summer season is simulated by increasing temperature at a constant rate from 1 to 100 iterations. There are other many factors which can change the concentration of salt particles including the shape of the substrate or crosswind effects. These effects are not included in the current study. The results plotted in fig. 15 and fig. 16 shows the behaviour of transport rate of salinity into coating when the concentration of salt particles varies depending on wind speed. The wind speed is increasing from $3 \mathrm{~m} / \mathrm{s}$ to $10 \mathrm{~m} / \mathrm{s}$ for the summer season in fig . 15 and wind speed is decreasing from 10 $\mathrm{m} / \mathrm{s}$ to $3 \mathrm{~m} / \mathrm{s}$ for the summer season in fig .16. High diffusion coefficient in summer accounts for the 
rise in transport rate of salt particles at high wind speed but in fig.16 simulation results show that although the diffusion coefficient is increased, the transport rate decreased due to decrease in salt deposition rate as a function of wind speed. Similarly, the varying salt concentration for winter season depending on wind speed is also simulated as shown in fig. 17 and in fig. 18. The winter season is simulated by decreasing temperature which accounts for decrease in diffusion coefficient from 1 to 100 iterations. The decrease in diffusion coefficient also decreases the transport of salt particles and decreasing wind speed also decreases the concentration of salt particles which is shown in fig. 17. Generally, the increase in deposition rate also increases the transport rate of salt particles but the variation in wind speed from high as $10 \mathrm{~m} / \mathrm{s}$ to low as $3 \mathrm{~m} / \mathrm{s}$ deposit low salt contents over surface and decrease in diffusion coefficient significantly reduces the salinity transport rate in fig. 17 results. The increase in wind speed from $3 \mathrm{~m} / \mathrm{s}$ to $10 \mathrm{~m} / \mathrm{s}$ is simulated for winter environment with decreasing diffusion coefficient in fig. 18. Although the diffusion coefficient is decreasing but high diffusion rate of salt particles resulted due to the presence of high salt particles due to high wind speed.

The transport rate of salinity depending on wind speed in uncontrolled environmental conditions near the sea is simulated by using eq. 7 as shown in fig. 19. The increase in the distance from sea also results in low salt deposition. The salt deposition rate is the highest near the sea and decreases as distance increases. The deposition rate of salt concentration also varies with wind speed. The transport rate of salt particles is simulated for different levels of wind speed as shown in fig. 19. As the wind speed increases the deposition rate and transport rate of salt particles also increases.

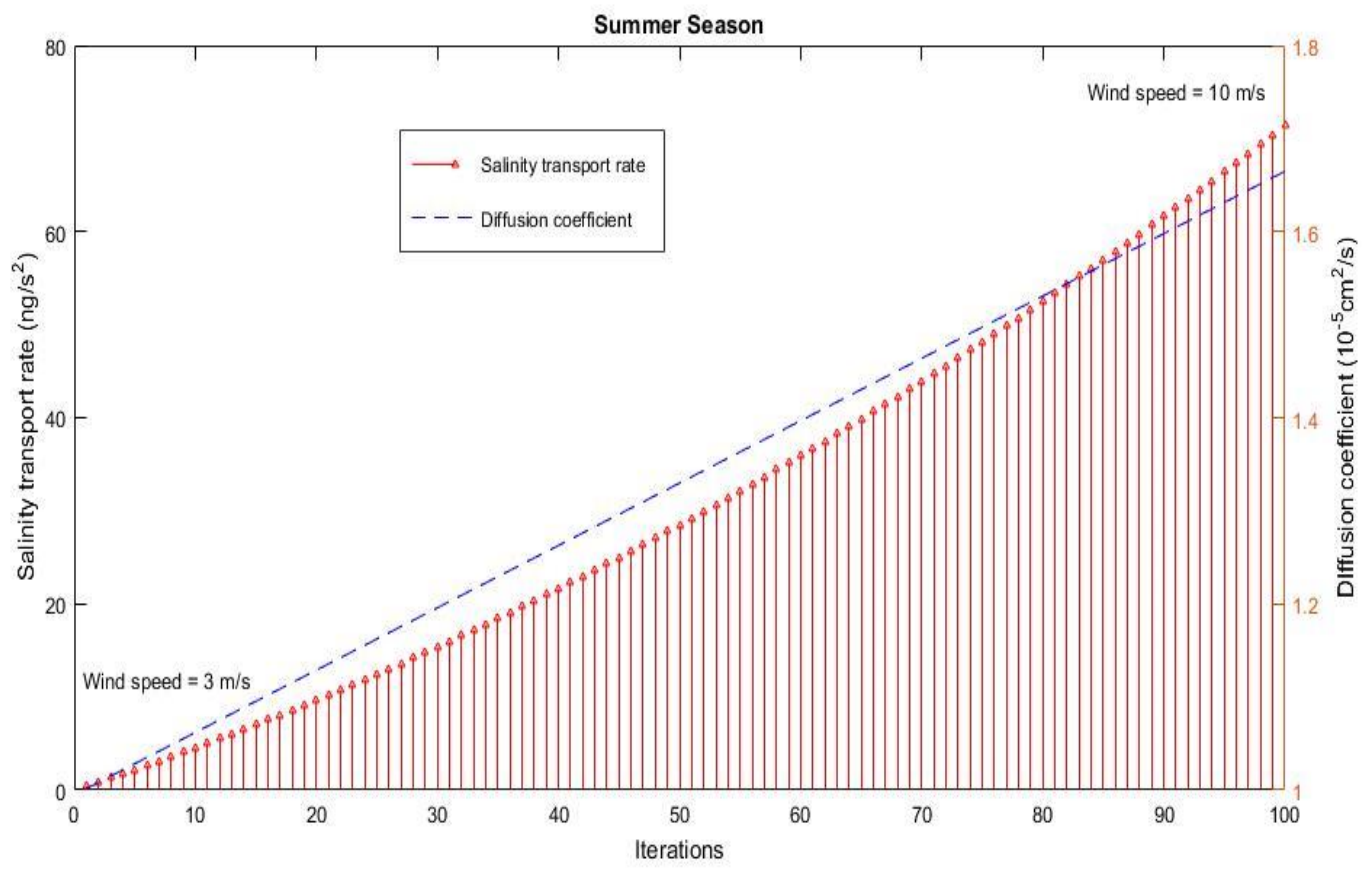

Figure 15 Salinity transport rate during the summer season for increasing wind speed 


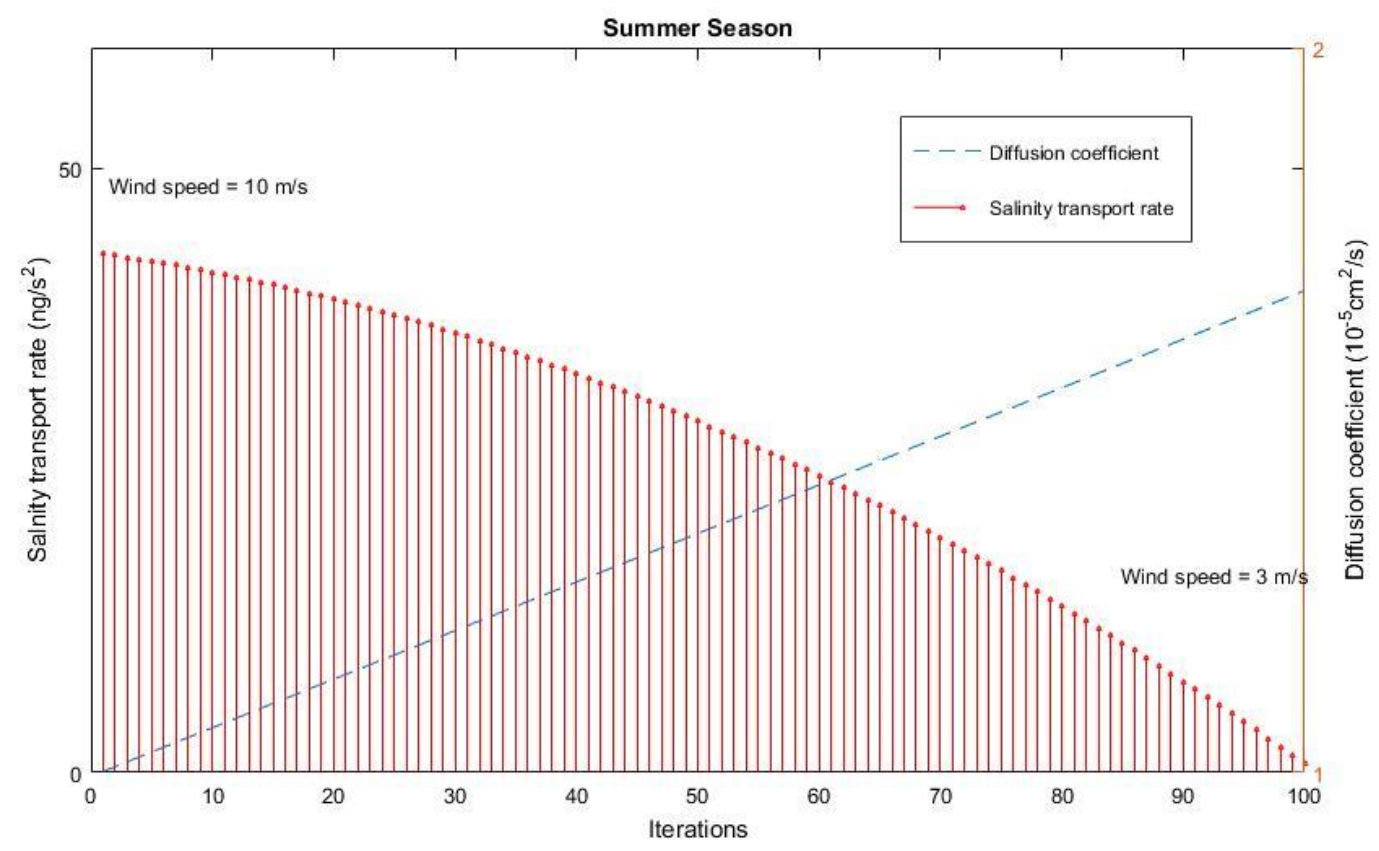

Figure 16 Salinity transport rate during the summer season for decreasing wind speed

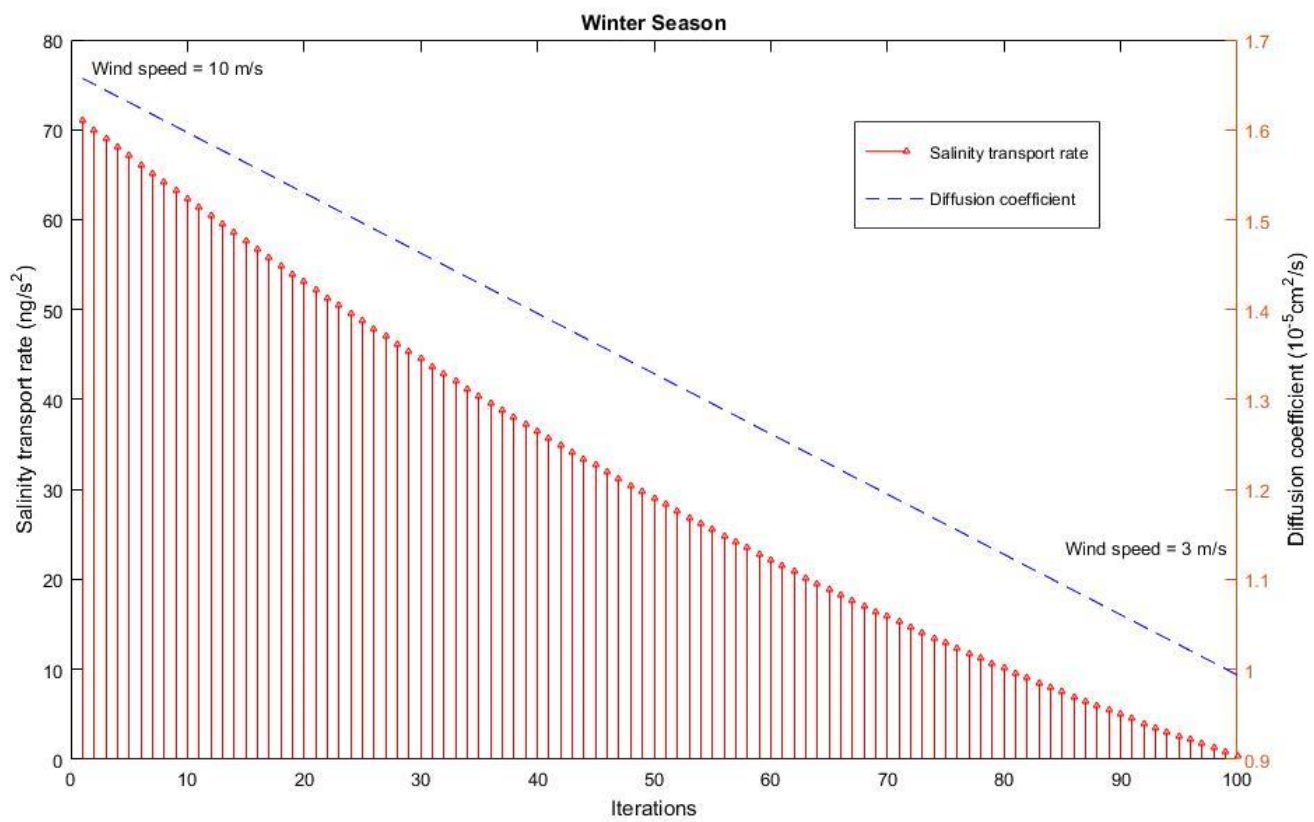

Figure 17 Salinity transport rate during the winter season for decreasing wind speed 


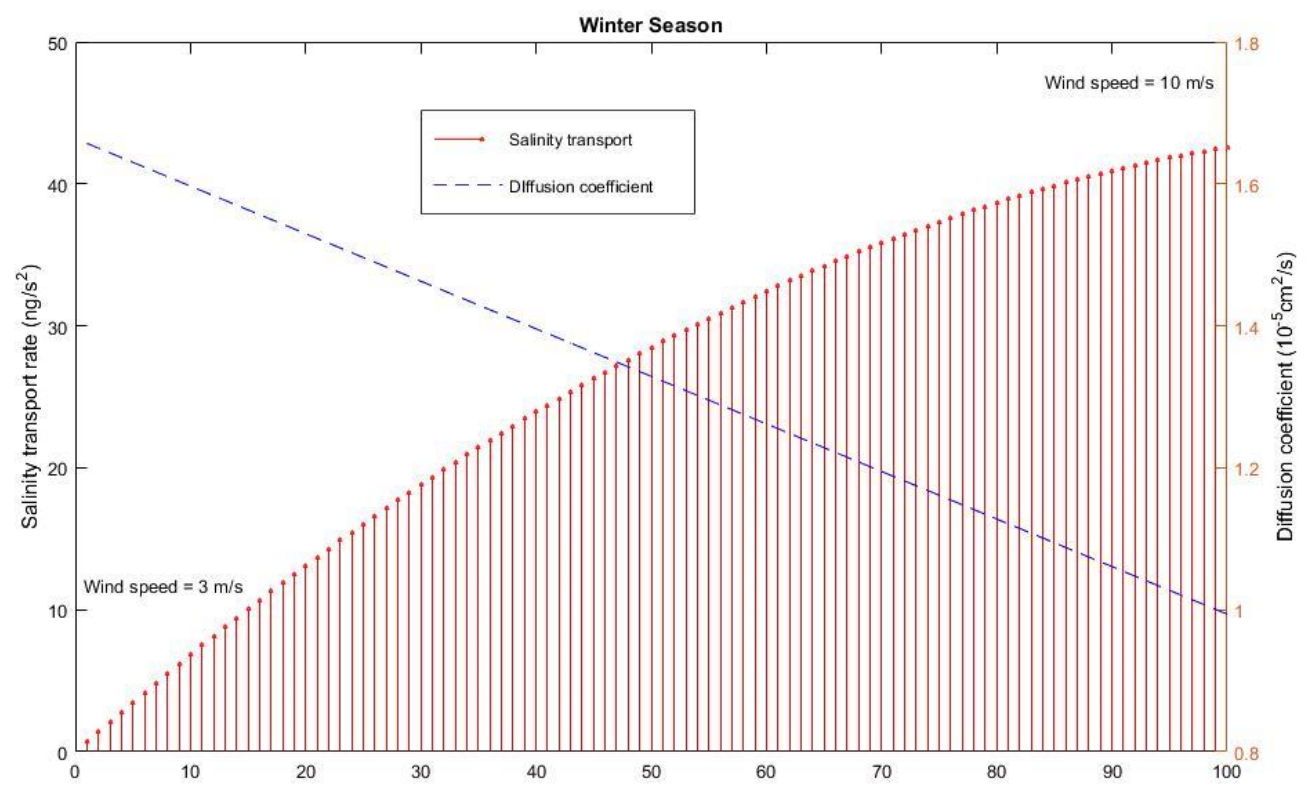

Figure 18 Salinity transport rate during the winter season for increasing wind speed

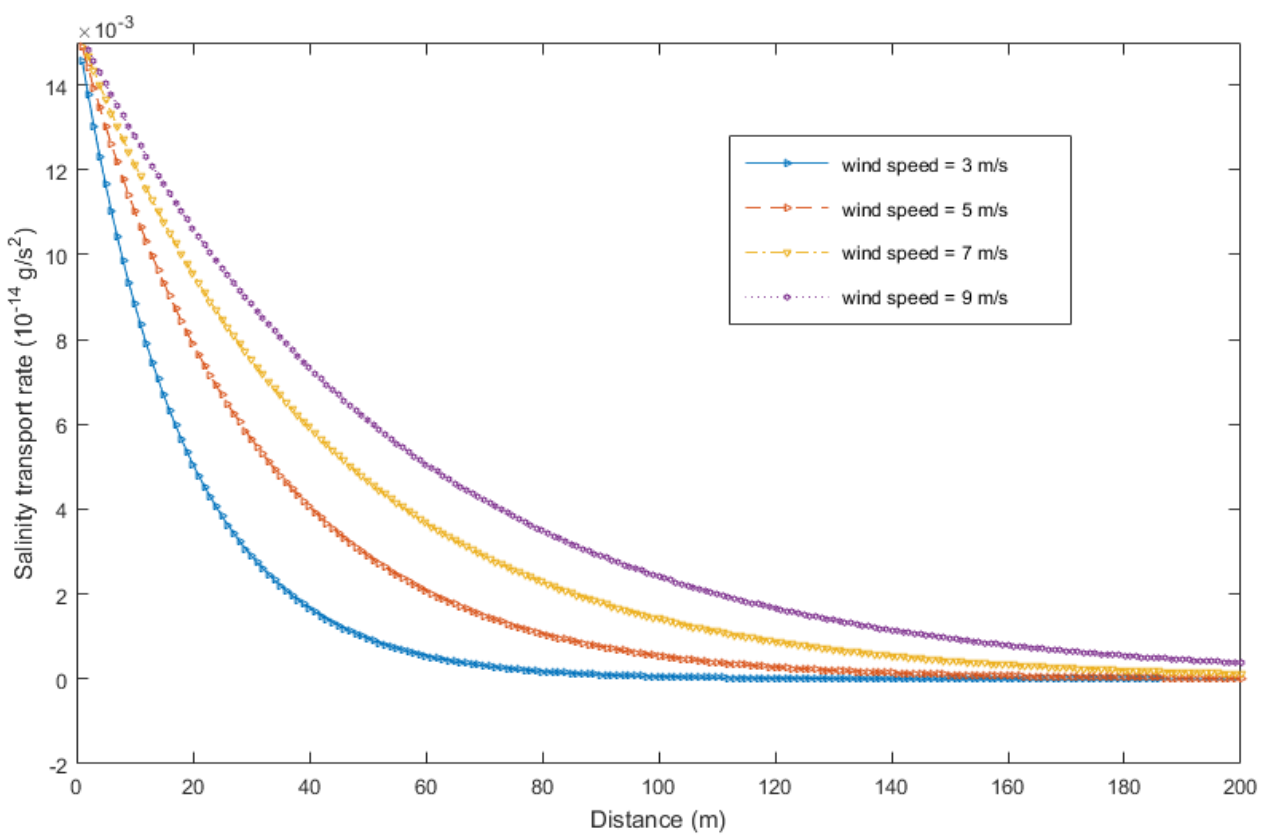

Figure 19 Salinity transport rate near sea depending on the distance from the sea 


\section{Conclusion}

This research provides a cost-effective yet efficient and reliable methodology to sustainably mitigate structural integrity issues within large vehicles and structures mainly through corrosion. The impact of meteorological parameters on large vehicles of historical importance operating under uncontrolled environmental conditions is measured by using linear polarisation resistance method. The solution for prior detection of corrosion damage at the initial stage for stationary as well as mobile vehicles operating remotely is also proposed in current work. The deposition of salt particles from the atmosphere is a major parameter which accounts for the amount of coating delamination and corrosion damage. The simulation study of coating delamination in winter and summer environmental conditions is also presented. The salinity transport rate near the sea is also modelled as a function of wind speed and simulation results are also reported. The algorithm presented in current work can be applied to assets operating at remote locations such as non-coastal, coastal and near sea environmental conditions to estimate the corrosion and coating damage using wind speed, temperature, humidity and time of exposure as input parameters. This framework is also applicable to conserve large vehicles of significant cultural and historical biographies for the future generations.

\section{Acknowledgements}

This research is jointly funded by Defence Science and Technology Laboratory (DSTL), Ministry of Defence (MoD) UK and Bournemouth University. The authors acknowledge their financial support and in-kind contributions.

\section{References}

1. NACE study estimates global cost of corrosion at \$2.5 trillion annually. 2016; Available from: https://inspectioneering.com/news/2016-03-08/5202/nace-study-estimates-global-costof-corrosion-at-25-trillion-ann.

2. Hertzberg. Cost of Corrosion to DoD. 2010; Available from: $<$ http://www .sae.org/events/dod/presentations/20 1 0/B3EricHerzberg.pdf $>$.

3. Feliu, S. and M. Morcillo, The prediction of atmospheric corrosion from meteorological and pollution parameters -I. Annual corrosion. Corrosion Science, 1993. 34(3): p. 403-414.

4. Feliu, S. and M. Morcillo, The prediction of atmospheric corrosion from meteorological and pollution parameters -II. Long-term forecasts. Corrosion Science, 1993. 34(3): p. 415-422.

5. Revie, R.W., Uhling's Corrosion Handbook (The ECS series of text and monographs). 2005, John Wiley, New York.

6. Mendoza, A.R. and F. Corvo, Outdoor and indoor atmospheric corrosion of non-ferrous metals. Corrosion Science, 2000. 42(7): p. 1123-1147.

7. Klinesmith, D.E., R.H. McCuen, and P. Albrecht, Effect of environmental conditions on corrosion rates. Journal of Materials in Civil Engineering, 2007. 19(2): p. 121-129.

8. Mahendra Adikari, N.M., Develpment of a Corrosion Model for Prediction of Atmospheric Corrosion of Mild Steel. American Journal of Construction and Building Materials, 2016. 1(1).

9. $\quad$ Melchers, R.E., Modelling The Long Term Atmospheric Corrosion Of Aluminium Alloys.

10. Altynova, M., et al. Engineering corrosion prediction model for aircraft structures. in 6th Joint FAA/DoD/NASA Aging Aircraft Conference, San Francisco, California. 2002.

11. Burns, R.M. and W.W. Bradley, Protective coatings for metals. 1967.

12. Huang, M.-W., et al., A mathematical model for cathodic delamination of coated metal including a kinetic pH-porosity relationship. Journal of the Electrochemical Society, 2008. 155(5): p. C279-C292.

13. Ogle, K., S. Morel, and N. Meddahi, An electrochemical study of the delamination of polymer coatings on galvanized steel. Corrosion science, 2005. 47(8): p. 2034-2052. 
14. Grundmeier, G., et al., Corrosion properties of chemically modified metal surfaces. Electrochimica acta, 1998. 43(1): p. 165-174.

15. Grundmeier, G., W. Schmidt, and M. Stratmann, Corrosion protection by organic coatings: electrochemical mechanism and novel methods of investigation. Electrochimica Acta, 2000. 45(15): p. 2515-2533.

16. Stratmann, M., R. Feser, and A. Leng, Corrosion protection by organic films. Electrochimica Acta, 1994. 39(8-9): p. 1207-1214.

17. Fürbeth, W. and M. Stratmann, The delamination of polymeric coatings from electrogalvanised steel-a mechanistic approach.: Part 1: delamination from a defect with intact zinc layer. Corrosion Science, 2001. 43(2): p. 207-227.

18. Stratmann, M., et al., The scanning Kelvin probe; a new technique for the in situ analysis of the delamination of organic coatings. Progress in Organic Coatings, 1996. 27(1): p. 261-267.

19. Allahar, K.N., M.E. Orazem, and K. Ogle, Mathematical model for cathodic delamination using a porosity-pH relationship. Corrosion Science, 2007. 49(9): p. 3638-3658.

20. Prawoto, Y. and B. Dillon, Failure analysis and life assessment of coating: the use of mixed mode stress intensity factors in coating and other surface engineering life assessment. Journal of failure analysis and prevention, 2012. 12(2): p. 190-197.

21. Prawoto, Y., Unified model for blister growth in coating degradation using weight function and diffusion concepts. Materials and Corrosion, 2013. 64(9): p. 794-800.

22. Saeed, A., Khan, Z., and Montgomery, E., Corrosion Damage Analysis and material Characterization of Sherman and Centaur - The Historic Military Tanks. Materials Performance and Characterization, February 6, 2013. 2(1): p. 30-44.

23. Saeed, A., et al., Material characterization and real-time wear evaluation of pistons and cylinder liners of the tiger 131 military tank. Tribology Transactions, 2013. 56(4): p. 637-644.

24. Nazir, M.H., et al., A model for cathodic blister growth in coating degradation using mesomechanics approach. Materials and Corrosion, 2015.

25. Nazir, M.H., et al., Modeling the Effect of Residual and Diffusion-Induced Stresses on Corrosion at the Interface of Coating and Substrate. Corrosion, 2015. 72(4): p. 500-517.

26. Saeed, A., et al., Non-destructive material characterisation and material loss evaluation in large historic military vehicles. Insight: Non-Destructive Testing and Condition Monitoring, 2011. 53(7): p. 382-386.

27. Nazir, M.H., et al., A predictive model for life assessment of automotive exhaust mufflers subject to internal corrosion failure due to exhaust gas condensation. Engineering Failure Analysis, 2016. 63: p. 43-60.

28. Saeed, A., Sustainable methodology of conserving historic military vehicles. 2013, Bournemouth University.

29. Saeed, A., Z.A. Khan, and M.H. Nazir, Time dependent surface corrosion analysis and modelling of automotive steel under a simplistic model of variations in environmental parameters. Materials Chemistry and Physics, 2016. 178: p. 65-73.

30. Nazir, M.H., Z.A. Khan, and K. Stokes, A holistic mathematical modelling and simulation for cathodic delamination mechanism - a novel and an efficient approach. Journal of Adhesion Science and Technology, 2015: p. 1-39.

31. Khan, Z.A., M. Grover, and M.H. Nazir, The Implications of Wet and Dry Turning on the Surface Quality of EN8 Steel, in Transactions on Engineering Technologies. 2015, Springer. p. 413-423.

32. Nazir, M.H., Z. Khan, and K. Stokes, Modelling of metal-coating delamination incorporating variable environmental parameters. Journal of Adhesion Science and Technology, 2014. 29(5): p. 392-423.

33. Nazir, M., et al., Modelling the Effect of Residual and Diffusion induced Stresses on Corrosion at the Interface of Coating and Substrate. Corrosion, 2015.

34. Nazir, M.H., Z.A. Khan, and K. Stokes, Optimisation of Interface Roughness and Coating Thickness to Maximise Coating-Substrate Adhesion - A Failure Prediction and Reliability Assessment Modelling. Journal of Adhesion Science and Technology, 2015. 29(14): p. 14151445. 
35. Nazir, M., Z.A. Khan, and K. Stokes, A unified mathematical modelling and simulation for cathodic blistering mechanism incorporating diffusion and fracture mechanics concepts. Journal of Adhesion Science and Technology, 2015. 29(12): p. 1200-1228.

36. Nazir, M.H., Z.A. Khan, and K. Stokes, Analysing the coupled effects of compressive and diffusion induced stresses on the nucleation and propagation of circular coating blisters in the presence of micro-cracks. Engineering Failure Analysis, 2016. 70: p. 1-15.

37. Saeed, A., et al., Non-destructive material characterisation and material loss evaluation in large historic military vehicles. Insight-Non-Destructive Testing and Condition Monitoring, 2011. 53(7): p. 382-386.

38. Nazir, M.H., A. Saeed, and Z. Khan, A comprehensive predictive corrosion model incorporating varying environmental gas pollutants applied to wider steel applications. Materials Chemistry and Physics, 2017. 193: p. 19-34.

39. Saeed, A., et al., Research Impact Of Conserving Large Military Vehicles Through A Sustainable Methodology. International Journal of Heritage Architecture, 2017. 1(2): p. 267274.

40. Nazir, M. and Z. Khan, A review of theoretical analysis techniques for cracking and corrosive degradation of film-substrate systems. Engineering Failure Analysis, 2016.

41. Bajwa, R., et al., Wear and Friction Properties of Electrodeposited Ni-Based Coatings Subject to Nano-enhanced Lubricant and Composite Coating. Acta Metallurgica Sinica (English Letters), 2016. 29(10): p. 902-910.

42. Khan, Z.A., et al., Fabrication and characterisation of electrodeposited and magnertronsputtered thin films. International Journal of Computational Methods \& Experimental Measurements, 2015. 3(2): p. 165-174.

43. Nazir, M.H. and Z. Khan, Maximising the interfacial toughness of thin coatings and substrate through optimisation of defined parameters. International Journal of Computational Methods and Experimental Measurements, 2015. 3(4): p. 316-328.

44. Bajwa, R.S., et al., Effect of bath ionic strength on adhesion and tribological properties of pure nickel and Ni-based nanocomposite coatings. Journal of Adhesion Science and Technology, 2016. 30(6): p. 653-665.

45. Bajwa, R.S., et al., Water-Lubricated Ni-Based Composite ( $\mathrm{Ni}-\mathrm{Al2O}$, $\mathrm{Ni}-\mathrm{SiC}$ and $\mathrm{Ni}-\mathrm{ZrO} 2$ ) Thin Film Coatings for Industrial Applications. Acta Metallurgica Sinica (English Letters), 2015. 29(1): p. 8-16.

46. Khan, Z.A., Latif, J., Nazir, H., Saeed, A. and Stokes, K., Predictive and prognostic modelling and simulation of coating failures due to corrosion and mechanical failures. International Journal of Computational Methods and Experimental Measurements, 2017.

47. Latif, J., Khan, Z., Nazir, H., Stokes, K. and Plummer, J., Life Assessment Prognostic Modelling for Multi-layered Coating Systems using Multi-disciplinary approach. Materials Science and Technology, 2017.

48. Khan, Z.A., et al., Sensor based corrosion condition monitoring of coating substrate system informed by fracture mechanics, electrochemistry and heat transfer concepts. 2017.

49. $\quad$ Latif, J., et al., Life assessment prognostic modelling for multi-layered coating systems using a multidisciplinary approach. Materials Science and Technology, 2017: p. 1-15.

50. McDonald, R., C. Unni, and R. Duce, Estimation of atmospheric sea salt dry deposition: wind speed and particle size dependence. Journal of Geophysical Research: Oceans, 1982. 87(C2): p. 1246-1250.

51. Morcillo, M., et al., Salinity in marine atmospheric corrosion: its dependence on the wind regime existing in the site. Corrosion Science, 2000. 42(1): p. 91-104.

52. Meira, G., et al., Modelling sea-salt transport and deposition in marine atmosphere zone-A tool for corrosion studies. Corrosion Science, 2008. 50(9): p. 2724-2731.

53. Meira, G., et al., Salinity of marine aerosols in a Brazilian coastal area-Influence of wind regime. Atmospheric Environment, 2007. 41(38): p. 8431-8441.

54. Blanchard, D.C. and A.H. Woodcock, The Production, Concentration, and Vertical Distribution of the Sea-Salt Aerosol. Annals of the New York Academy of Sciences, 1980. 338(1): p. 330-347. 
55. Lovett, R., Quantitative measurement of airborne sea-salt in the North Atlantic. Tellus, 1978. 30(4): p. 358-364.

56. worldweatheronline. Available from: https://ja.worldweatheronline.com/.

57. Saeed, A., Z.A. Khan, and E.L. Montgomery, Corrosion Damage Analysis and material Characterization of Sherman and Centaur-The Historic Military Tanks. Materials Performance and Characterization, 2013. 2(1): p. 30-44.

58. Saeed, A., Z.A. Khan, and M.H. Nazir, An optimised approach of protecting and sustaining large vehicle system. Sustainability, 2015. 7(12): p. 16451-16464.

59. Saeed, A., Sustainable methodology of conserving historic military vehicles, in School of Design, Engineering \& Computing. 2013, Bournemouth University. p. 206.

60. Wagner, C. and W. Traud, Concerning the evaluation of corrosion reactions by superposition of electrochemical partial reactions and concerning the potential formation on mixed electrodes. Z. Elektrochem, 1938. 44(391): p. 52.

61. Brown, D.W., et al. Linear Polarization Resistance Sensor Using the Structure as a Working Electrode. in Proceedings of the Second European Conference of the Prognostics and Health Management Society, Nantes, France. 2014.

62. Nims, D.K., et al., LUC-2-1682 Long Term Maintenance of the Anthony Wayne Suspension Bridge Main Cables. 2017, Ohio Department of Transportation, Office of Statewide Planning $\&$ Research.

63. Nazir, M., et al., Modeling the Effect of Residual and Diffusion-Induced Stresses on Corrosion at the Interface of Coating and Substrate. Corrosion, 2015. 72(4): p. 500-517.

64. Bastidas-Arteaga, E., et al., A comprehensive probabilistic model of chloride ingress in unsaturated concrete. Engineering Structures, 2011. 33(3): p. 720-730.

65. Levin, Z. and W.R. Cotton, Aerosol pollution impact on precipitation: a scientific review. 2008: Springer Science \& Business Media.

66. Basu, D. and D. Khan, Short communication on role of different variables on atmospheric corrosion in marine environment-Effect of proximity to sea. 1972.

67. Rajagopalan, K., et al., Atmospheric Corrosion of Steel in Some Tropical Locations in India. Proc. 3rd Int. Cong. on Metallic Corrosion. 4: p. 532.

68. Dutra, A. and R. VIANNA, Atmospheric Corrosion. 1982, John Wiley, New York.

69. Dutra, A. and R. Vianna. Atmospheric Corrosion Testing in Brazil, to be presented at the. in International Symposium on Atmospheric Corrosion. 1980.

70. McMahon, T. and P. Denison, Atmosf. Environment, 1979. 13: p. 571-585.

71. Laidler, K.J., The development of the Arrhenius equation. J. Chem. Educ, 1984. 61(6): p. 494.

72. Samson, E., J. Marchand, and K. Snyder, Calculation of ionic diffusion coefficients on the basis of migration test results. Materials and Structures, 2003. 36(3): p. 156-165.

73. Baştuğ, T. and S. Kuyucak, Temperature dependence of the transport coefficients of ions from molecular dynamics simulations. Chemical physics letters, 2005. 408(1): p. 84-88.

74. Nazir, M., Z. Khan, and K. Stokes, Modelling of metal-coating delamination incorporating variable environmental parameters. Journal of Adhesion Science and Technology, 2015. 29(5): p. 392-423. 